\title{
Signaling Interplay between Bone Marrow Adipose Tissue and Multiple Myeloma cells
}

\author{
Carolyne Falank ${ }^{1}$, Heather Fairfield ${ }^{1}$ and Michaela R. Reagan ${ }^{1,2,3 *}$ \\ ${ }^{1}$ Reagan Laboratory, Maine Medical Center Research Institute, Scarborough, ME, USA, ${ }^{2}$ School of Biomedical Sciences \\ and Engineering, University of Maine, Orono, ME, USA, ${ }^{3}$ School of Medicine, Tufts University, Boston, MA, USA
}

\section{OPEN ACCESS}

Edited by:

Erica Lynn Scheller, Washington University

School of Medicine, USA

Reviewed by:

Graziana Colaianni,

University of Bari, Italy

Izabela Podgorski,

Wayne State University

School of Medicine, USA

*Correspondence:

Michaela R. Reagan

mreagan@mmc.org

Specialty section:

This article was submitted

to Bone Research,

a section of the journal

Frontiers in Endocrinology

Received: 03 May 2016 Accepted: 03 June 2016 Published: 17 June 2016

Citation:

Falank C, Fairfield H and Reagan MR

(2016) Signaling Interplay between

Bone Marrow Adipose Tissue and Multiple Myeloma cells.

Front. Endocrinol. 7:67.

doi: 10.3389/fendo.2016.00067
In the year 2000, Hanahan and Weinberg (1) defined the six Hallmarks of Cancer as: self-sufficiency in growth signals, evasion of apoptosis, insensitivity to antigrowth mechanisms, tissue invasion and metastasis, limitless replicative potential, and sustained angiogenesis. Eleven years later, two new Hallmarks were added to the list (avoiding immune destruction and reprograming energy metabolism) and two new tumor characteristics (tumor-promoting inflammation and genome instability and mutation) (2). In multiple myeloma (MM), a destructive cancer of the plasma cell that grows predominantly in the bone marrow (BM), it is clear that all these hallmarks and characteristics are in play, contributing to tumor initiation, drug resistance, disease progression, and relapse. Bone marrow adipose tissue (BMAT) is a newly recognized contributor to MM oncogenesis and disease progression, potentially affecting MM cell metabolism, immune action, inflammation, and influences on angiogenesis. In this review, we discuss the confirmed and hypothetical contributions of BMAT to MM development and disease progression. BMAT has been understudied due to technical challenges and a previous lack of appreciation for the endocrine function of this tissue. In this review, we define the dynamic, responsive, metabolically active BM adipocyte. We then describe how BMAT influences MM in terms of: lipids/metabolism, hypoxia/angiogenesis, paracrine or endocrine signaling, and bone disease. We then discuss the connection between BMAT and systemic inflammation and potential treatments to inhibit the feedback loops between BM adipocytes and MM cells that support MM progression. We aim for researchers to use this review to guide and help prioritize their experiments to develop better treatments or a cure for cancers, such as MM, that associate with and may depend on BMAT.

Keywords: bone marrow adipose, BMAT, MAT, adipocyte, microenvironment, multiple myeloma, fatty acids, bone metastasis

\section{INTRODUCTION}

Within the last few years, researchers have begun to explore the mechanistic relationship between bone marrow (BM) adipose and adjacent tumors such as multiple myeloma (MM), which is a cancer characterized by clonal proliferation of transformed plasma cells (3). The clinical potential of such a research avenue is yet unknown, but preclinical data suggest that targeting BM adipose tissue (BMAT) could be an effective cancer treatment. BMAT also interacts with bone cells and other immune cells, highlighting indirect ways in which BMAT may affect MM disease progression 
(Figures 1 and 2). Clearly, there needs to be more research in this area. MM cells accumulate within the BM and are highly dependent on this unique biochemical and cellular niche, as we have recently reported (4). Only recently, the idea that adipocytes may accelerate or support MM has come to researchers' attention. The BM adipocyte may play a role in MM bone homing, tumor progression, drug resistance, recurrence, or osteolysis, due to local paracrine, endocrine, or metabolic signals. Just as understanding the relationship between osteoclasts and tumor cells led to the development of highly effective antiresorptive agents (bisphosphonates), and understanding the relationship between osteoblasts and MM cells has led to bone anabolic agent research, we propose that a clearer perception of the BMAT-MM cell relationship would identify novel ways to more effectively treat or prevent MM or MM-associated bone disease.

As adipose tissue is one of the main components within the BM niche, especially in old age, obesity, and upon radiation, there is clearly a need to characterize BMAT-MM relations. In this review, we discuss the current evidence regarding the signaling pathways driving effects of BMAT on myelomagenesis and progression. This review should guide future research strategies toward developing novel therapies to target $\mathrm{MM}$ or $\mathrm{MM}$-induced bone disease through focusing on BMAT and its derivatives.
For an overview of the contributions of the other components of the $\mathrm{BM}$, we refer the reader to a few other recent reviews (4-6).

\section{DEFINING MULTIPLE MYELOMA AND MYELOMA-ASSOCIATED BONE DISEASE}

Multiple myeloma is a cancer resulting from the accumulation of genetic mutations within an immune cell, called a plasma cell. Along the uncontrolled myeloma cell growth, MM also causes disruption of the BM and cancer-induced bone disease (4). Myeloma accounts for $\sim 1-2 \%$ of cancers and $\sim 13-15 \%$ of all blood cancers (7) and is characterized by clonal proliferation of tumor cells in the BM, monoclonal protein spikes in the blood or urine, and organ shutdown (3). In August 2015, a revised staging system was released for myeloma from the International Myeloma working group that categorized MM as stage I, II, or III, based on disease risk levels, such as chromosomal abnormalities and serum lactate dehydrogenase (LDH) levels (8). At a median follow-up of 46 months, the society found a 5-year overall survival rate of $82 \%$ in stage I, $62 \%$ in stage II, and $40 \%$ in stage III. The 5-year progression-free survival rates were 55, 36 , and $24 \%$, respectively, for these groups. Although treatments for MM have significantly improved since the disease was first

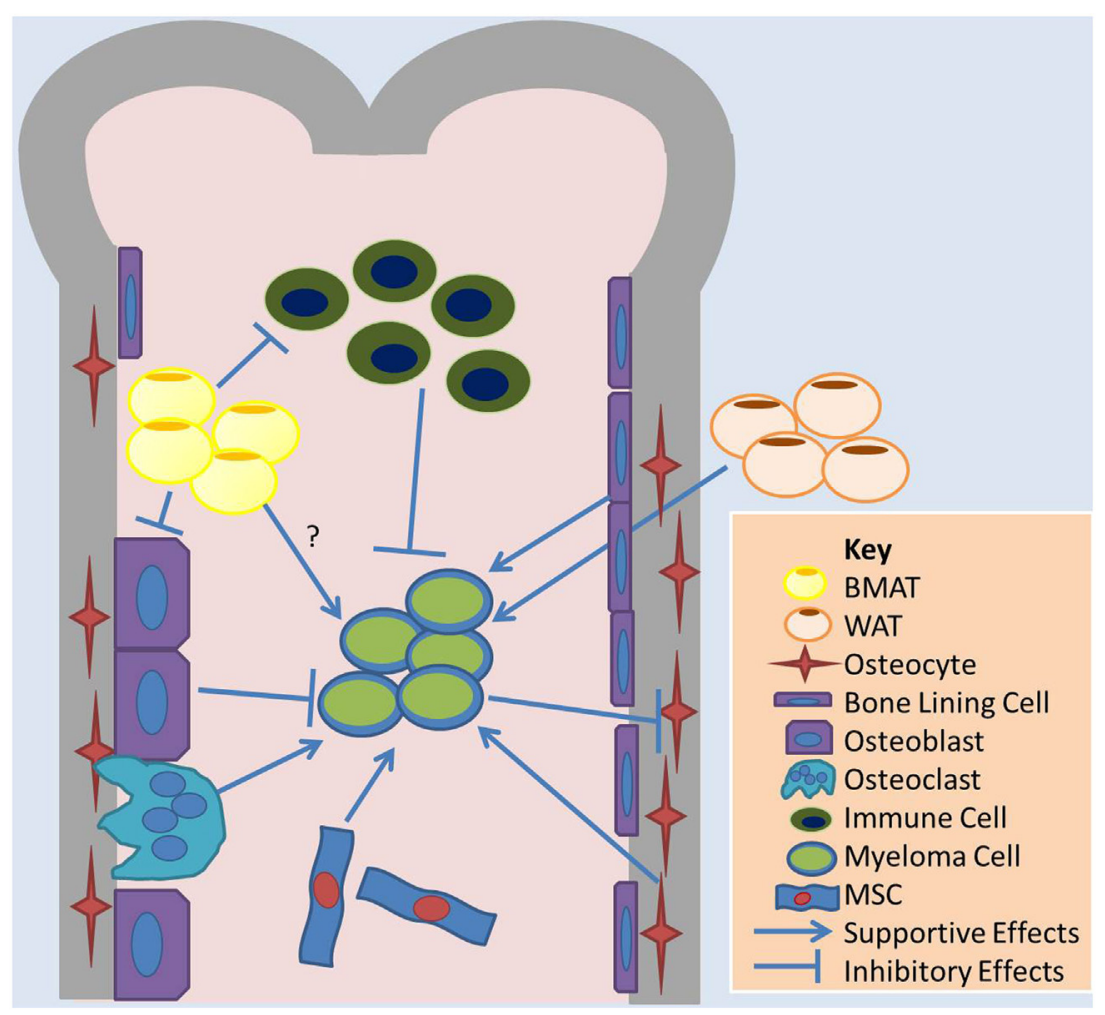

FIGURE 1 | Overview of cell-cell interactions relevant to BMAT and adipose effects on MM. Bone marrow adipose tissue (BMAT) may contribute to multiple myeloma (MM) growth in the marrow through indirect mechanisms, such as influences on other cells in the marrow, or direct mechanisms. BMAT has some evidence of inhibiting osteoblasts and the anticancer effects of immune cells and supporting osteoclasts and MM cell. White adipocytes, the basis of white adipose tissue (WAT), may also contribute to tumor growth in the bone marrow through systemic signaling pathways. MM cells also induce apoptosis in osteocytes, which may support MM cells. Bone lining cells and mesenchymal stromal cells (MSCs), as well as osteoclasts, support MM while osteoblasts may induce dormancy in MM cells. 


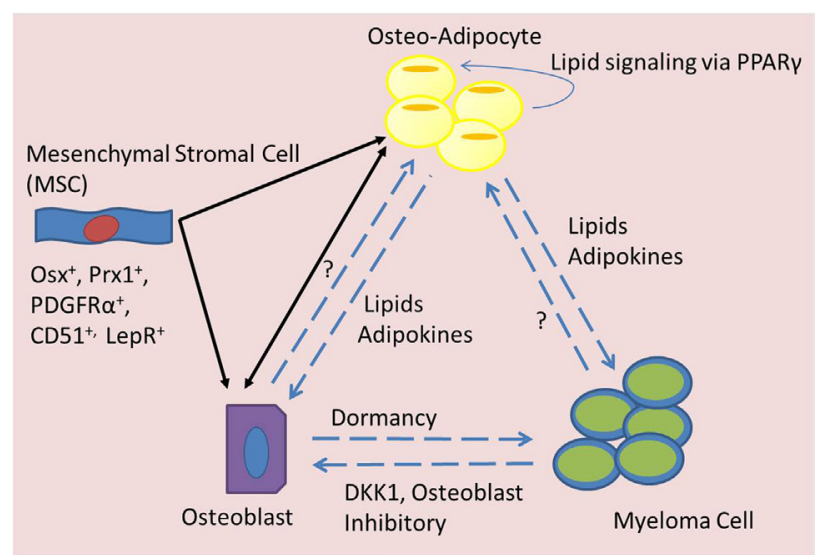

FIGURE 2 | Signaling mediators of BMAT in MM. Bone marrow mesenchymal stromal cells (MSCs) can differentiate into adipocytes or osteoblasts, which may have an elasticity and ability to transdifferentiate across lineage lines and also signal to each other (black arrows). Both osteo-adipocytes (adipocytes in the bone marrow) and osteoblasts are able to signal to each other and to myeloma cells (blue dotted arrows). Myeloma cells are known to inhibit osteoblasts, but their effects on osteo-adipocytes are unknown. Osteoblasts seem to induce dormancy in myeloma cells, but their effects on adipocytes are unknown. Osteo-adipocytes produce lipids and adipokines that likely influence MM and bone cells. Lipids from osteo-adipocytes can act as PPAR $\gamma$ ligands and may thus stimulate a positive feedback loop, inducing more BMAT accumulation in the marrow.

named in 1873 by J. von Rustizky (9), MM remains considered an incurable cancer. The disease is more common in males than females, African-Americans than Caucasians, older rather than younger people (the median age at diagnosis is 70), and in individuals with a family history of lymphatohematopoietic cancers (3). Obesity also has been found to be risk factor for $\mathrm{MM}$ in numerous studies and a pooled analysis of 20 prospective studies (10).

Myeloma arises from an asymptomatic precursor disease termed monoclonal gammopathy of undefined significance (MGUS) that progresses to smoldering myeloma and, eventually, overt, symptomatic myeloma (3). While early chromosomal abnormalities, such as immunoglobulin heavy chain translocations or trisomies, are present in both MGUS and MM, secondary translocations or mutations involving oncogenes (e.g., MMSET, $M Y C, M A F B, I R F 4, F G F R 3, R A S$ family members, among many others) (11) or tumor suppressors (e.g., CDKN2A, CDKN2C, or TP53) are unique to MM and absent in MGUS (12). Interestingly, deep sequencing of 203 tumor-normal paired samples revealed intratumor genetic heterogeneity with recurrent mutation occurring early or late during tumor evolution to be common in MM (12). Other pathways, such as the phosphatidylinositol 3-kinase (PI3K) pathway (important for cell division, growth, survival, and motility), can also be hyperactivated in MM (due to external signaling from the bone milieu) and serve as a good target, despite a lack of mutations in the pathway (13). Cells from the immune system also appear to be abnormal in MM and contribute to MM progression through expression of proteins such as TNFSF14 $(6,14)$ or by inducing T-cell immunosenescence $(15)$.
In sum, the genetic heterogeneity in MM may limit effectiveness of tumor-targeted therapy, indicating that better results may be obtained by targeting the bone microenvironment to impede MM and MM-induced bone disease.

Multiple myeloma-induced bone disease is the general term for the destruction of bone (associated with severe pain, pathologic fractures, and spinal cord compression) that occurs during myeloma colonization of the BM. Upon engrafting within the BM niche, MM cells accelerate osteoclastogenesis through expression of molecules, such as RANKL, MMP-13 (16), and Decoy receptor 3 (DcR3), a member of the tumor necrosis factor (TNF) receptor superfamily (17). MM cells also inhibit osteoblastogenesis, disrupting the normal equilibrium between these two processes (18), through expression of Dickkopf-1 (DKK-1) and inducing upregulation of SOST in local osteocytes. Chemokines and cytokines associated with osteolysis in MM include CCL3, CCL20, and Activin-A (19). Increased osteoclastic activity leads to hypercalcemia (elevated calcium in the blood) and bone lesions. Therefore, the mnemonic for the signs and symptoms of MM is CRAB: C, elevated Calcium in the blood stream; $R$, renal failure due to elevated circulating protein (immunoglobulin); A, anemia, or lack of red blood cells due to tumor crowding into the BM; and B, bone lesions (4). Much research has been directed toward inhibiting the "vicious cycle" of osteoclast activation using bisphosphonates, OPG, or RANKL antibodies (denosumab) (6, 20-22). Using bone anabolic agents to regrow bone by stimulating osteoblasts (23) is another therapy for healing bone lesions and potentially inducing quiescence in MM cells (24). Lately, research has also focused on targeting MM cell homing to the BM, either through targeting the unique BM vasculature $(25,26)$, the molecules (e.g., sugars) and proteins on this vasculature $(27,28)$, or the chemokines (e.g., SDF1) within the BM (29-31). Other marrow cellular components, such as mesenchymal stromal cells (MSCs) (5, 32-34), osteocytes (35), and adipocytes, as described in this review, are also potential new avenues to regrow bone, inhibit bone loss, or inhibit MM survival or proliferation.

\section{DEFINING THE BM ADIPOCYTE}

The anatomy and physiology of adipose tissue, as reviewed by Colaianni et al. (36), can direct energy storage (in white adipose), energy use (in brown adipose, for heat generation), or a combination of these and other functions yet to be discovered, as seen in BMAT. BMAT is a distinct adipose depot distinguishable from other adipose depots based on differences in phenotype, stress and diet response, physiological roles, gene expression, and origin. It has been found to affect the disease course of cancer, osteoporosis, and other pathologies of the bone (37). Composed of BM adipocytes and infiltrating inflammatory cells, BMAT has a gene expression pattern that overlaps with both white adipose tissue (WAT) and brown adipose tissue (BAT) (38). Like WAT, BMAT stores energy in the form of unilocular intracellular lipid droplets, opposed to multilocular droplets, as seen in BAT (39). Yet, WAT and BMAT are different in some other regards: BMAT expression of certain proteins [e.g., Dio2, peroxisome proliferator-activated receptor (PPAR) gamma coactivator 
1-alpha (PGC-1 $\alpha$ ), and FOXC2] (40) is much higher than WAT expression, and while WAT volume decreases during starvation, BMAT volume increases perhaps highlighting its evolutionary role as the last energy store during starvation (41, 42). Gene expression level is also different for WAT and BMAT, as seen in the following genes: uncoupling protein 1 (UCP1), type II iodothyronine deiodinase (Dio2), PGC- $1 \alpha$, PR domain containing 16 (PRDM16), Forkhead box protein C2 (FOXC2), and leptin (43). Yet, these adipose depots are similar in other regards. For example, in response to obesity in mice and humans, both WAT and BMAT volumes increase due to increased adipocyte size and quantity, suggesting that both may act as reservoirs for excess energy storage $(44,45)$. Overall, due to the hard-to-access location of BMAT, its interspersion with many other BM cells, and its absence from hematoxylin and eosin stain histology slides due to processing challenges, BMAT has been inadvertently ignored in the BM niche for years and is thus poorly understood relative to other adipose depots.

Adipose depot properties also diverge within the BM and are both cell- and microenvironment-dependent. Adipose in the distal long bone BM is termed "constitutive marrow adipose tissue" (cMAT) and proximal adipose is termed "regulated marrow adipose tissue" (rMAT), as it is commonly "regulated," or modified, rather than constitutively present (37). This suggests that BM adipocytes may be either location dependent or composed of two subpopulations of adipocytes; this remains under investigation. In rabbits, humans, and mice, MAT develops differently based on its location in the skeleton (46). cMAT, often termed "yellow adipose" due to its yellow appearance in the marrow, is found in the distal tibia and tail (caudal vertebra) of rodents and forms at birth, whereas $r M A T$ accumulates with aging in proximal femora and more proximal vertebrae. $c M A T$ volume can be measured by MRI in humans or by osmium microcomputed tomography in rodents and is constitutively present $(47,48)$. cMAT is proportional to bone mass in many cases; for example, the distal tibia, which is loaded with cMAT relative to the proximal tibia, and the caudal vertebrae, again loaded with cMAT relative to the lumbar vertebrae, also have more trabecular bone mass $(46,49)$. Interestingly, these sites with high cMAT/yellow MAT (distal tibia metaphysis, first lumbar vertebra), compared to regions with more red marrow (proximal tibia metaphysis or fifth caudal vertebra), also appear protected from bone loss induced by ovariectomy in rats (50).

Constitutive marrow adipose tissue may negatively impact hematopoiesis and maintain hematopoetic stem cells (HSCs) in a quiescent state (51). rMAT is often, but not always, correlated with low bone mass and is regulated by factors including diet, drugs, age, and other endocrine and paracrine influences (42, 52-56). Interestingly, both cell-autonomous factors and the BM microenvironment appear to govern BMAT formation. In one study, although differentiation potential was found to be generally decreased in BM-MSCs, donor age was found to affect osteogenic differentiation of BM MSCs more than it affects adipogenic differentiation $(57,58)$. In another study, human adiposederived stem cells showed a shift in favor of adipogenesis with increased age (59). Yet, as demonstrated in a transplant study of $\mathrm{BM}$ cells into old and young mice, researchers found older hosts induced greater adipogenic lineage allocation than younger hosts did for the same transplanted MSCs, demonstrating the context and source influences on adipogenesis (60).

Lineage tracing experiments demonstrate that BMAT arises from an osterix-positive BM mesenchymal progenitor cell, common to osteoblasts, chondrocytes, and other BM stromal cells (61) (Figure 2). Interestingly, BM adipocytes cells are more closely related to osteoblasts and chondrocytes than are peripheral WAT adipocytes (62). One study found that a quiescent, leptin receptor-positive $\left(\mathrm{LepR}^{+}\right)$progenitor cell [stem cell factor (SCF) and CXCL12 expressing, and Nestin low] is the progenitor cell for most BM adipocytes, osteoblasts, and chondrocytes. This cell is also the progenitor to new cells formed after irradiation or fracture in the bone (61). These progenitors also express Prx1, PDGFR $\alpha$, and CD51 markers expressed by BM-MSCs, emphasizing the need for more thorough bone progenitor classification (61). The plasticity or elasticity between different progenitors and their progeny may complicate the unequivocal identification of phylogenic lines, and differences between mouse and human cells and proteins may also further complicate these studies. A better understanding of the lineage pathways of BM cells would provide insight into a wide array of pathophysiologies.

\section{BONE MARROW ADIPOCYTE INFLUENCES ON MM}

High body mass index (BMI) is correlated with an increased risk of developing $\mathrm{MM}$ and is associated with higher levels of $\mathrm{BM}$ adiposity, perhaps creating an optimal microenvironment, or "soil," in which MM can engraft and grow (63-65). BM adipocytes isolated from MM patient femoral biopsies have been shown to support myeloma growth in vitro and may protect MM cells from chemotherapy-induced apoptosis $(66,67)$. These results suggest that elevated adipocyte numbers support MM advancement. By excreting free fatty acids (FFAs) and producing a plethora of signaling molecules [e.g., adipokines (leptin, adiponectin, adipsin, etc.) and growth factors (e.g., IL-6, TNF $\alpha$, MCP-1, insulin-like growth factor 1 (IGF-1), and insulin)], BM adipocytes are both an energy source and an endocrine signaling factory (Figures 3 and 4). Many of these BMAT-derived signaling molecules may promote myelomagenesis and enhance tumor growth $(42,68)$ (Figure 3). In this section, we explore the potential contributions of BMAT to MM progression.

\section{Lipids and Cellular Metabolism}

When metastatic ovarian cells colonize the omentum (the fatty membrane surrounding the stomach and abdominal organs), they induce adipocytes to release lipids, which are subsequently utilized as energy for tumor cell proliferation. This process transforms the soft, flexible omentum fat pad into a hardened, tumor-infiltrated membrane with few remaining adipocytes in a process termed "omental caking" (69). This same phenomenon may occur in adipose-rich BM cavities, and fuel-switching in MM cells and the use of fatty acids could prove advantageous to MM cells owing to the high energy content of lipids and lipidinduced cell signaling changes that lead to drug resistance. Yet, 


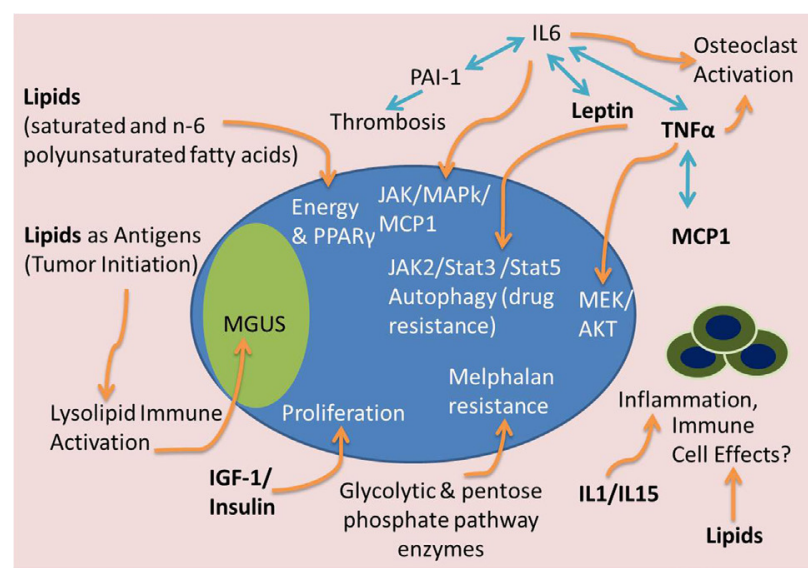

FIGURE 3 | Tumor-supportive effects of BMAT. Many factors from BMAT may induce MM tumor growth and disease progression. Lipids may serve as a fuel source for tumor cells, antigens to stimulate precursor disease initiation [i.e., monoclonal gammopathy of undefined significance (MGUS)], or inhibitors of the immune system. IGF-1 and insulin can accelerate tumor proliferation. IL-1 and IL-15 can have effects on immune cells and inflammatory molecules to support MM growth and immune evasion. Complex interactions between TNF $\alpha$, IL-6, leptin, PAI-1, and MCP-1 can lead to osteoclast activation, thrombosis, and JAK/Stat/MAPK signaling to cause osteolysis, thrombosis and tumor cell migration, drug resistance, and proliferation. Glycolytic and pentose phosphate pathway enzyme upregulation, potentially found in high energy states, can also lead to melphalan resistance in $\mathrm{MM}$ cells.

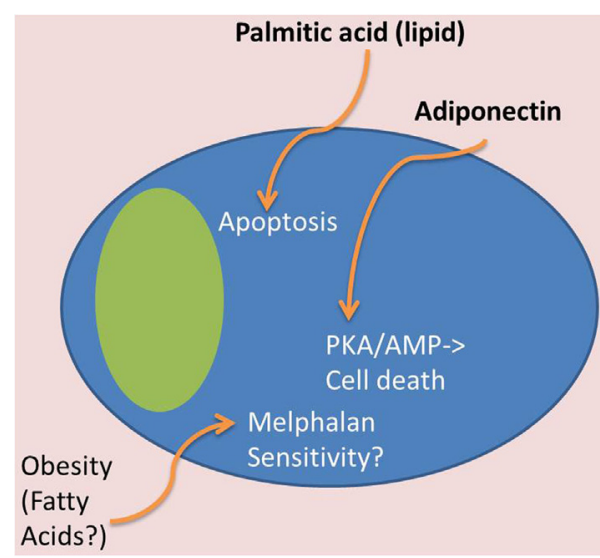

FIGURE 4 | Tumor-suppressive effects of BMAT. In contrast to Figure 3 certain adipocyte-derived factors may have tumor-suppressive effects. For example, obese patients may have tumor cells that are more melphalan sensitive, which may be due to lipid effects on MM cells. Also, certain lipids, such as palmitic acid, can induce apoptosis in MM cells, and adiponectin, derived from adipose tissue, can induce cell death through the PKA/AMP signaling pathways.

this story is not clear cut. For example, despite the fact that obesity correlates with increased risk of MM, one study found that obese and severely obese patients had superior overall survival and progression-free survival after high-dose melphalan and autologous hematopoietic stem cell transplantation compared with normal and overweight patients (70). Yet, other research found that melphalan-resistant MM cells upregulate glycolytic and pentose phosphate pathway (PPP) enzymes and downregulate tricarboxylic acid (TCA) cycle proteins (71). Together, these reports suggest that high BMI patients fuel MM cells via fatty acids, while hyperglycolytic diabetic patients could support MM cells via glycolysis, and that either metabolic pathways could support drug resistance. Additionally, some lipids, such as palmitic acid, have shown direct anti-myeloma effects (72).

Recent new data suggest that certain drugs, such as arsenic trioxide $\left(\mathrm{As}_{2} \mathrm{O}_{3}\right)$, may induce anti-MM effects by affecting the sphingolipid pathways in MM cells. U266 MM cells treated with $\mathrm{As}_{2} \mathrm{O}_{3}$ displayed decreased lipid metabolites in this pathway including dihexosylceramide (Hex2Cer), sphingosine-1-phosphate (S1P), and sphinganine-1-phosphate (dhS1P) (73). As sphingolipids are a major group of membrane bioactive lipids, these changes could not only affect FFA metabolism but also membrane fluidity and cell-cell signaling. Further, complexity arises from the fact that sphingolipids and their metabolites also act as signal transduction messengers, regulating diverse cellular events such as cell cycle arrest or apoptosis, proliferation, cancer development, and multidrug resistance, as recently reviewed in Ref. (74). Increased fatty acid levels (saturated and n-6 polyunsaturated fatty acids) have also been observed in MM patient versus healthy donor blood serum (75). Lipid profiles differ between MM cells and plasma cells, such as the levels of glycerophospholipids [specifically phosphatidylcholine (16:0/20:4)] (76), which suggest potential therapeutic avenues based on lipid biochemistry.

Autophagy, the process by which intracellular proteins and organelles are degraded in lysosomes, is a protective process through which MM cells protect themselves from unfolded or misfolded proteins (77). Certain lipids can induce autophagy in hematological malignancies, but other lipids can induce tumor cell survival, proliferation, or cell death, so it is important to understand how different sphingolipids and their metabolizing enzymes cooperatively exert their functions (74). Modulating cholesterol metabolism in myeloma cells, in particular the sterols zymosternol and desmosterol, has also been shown to mediate autophagy signaling (78). Overall, it is clear that lipids may affect autophagy of MM cells.

New data also suggest that lipids may be drivers of monoclonal gammopathies, such as MM and MGUS, by acting as antigens for plasma-cell-derived antibodies (Figure 3). Evidence of this comes from data showing that clonal immunoglobulin in $33 \%$ of sporadic human monoclonal gammopathies is specific for the lysolipids lysoglucosylceramide (LGL1) and lysophosphatidylcholine (LPC) (79). Nair et al. reported that substrate reduction ameliorated Gaucher's disease-associated gammopathy in mice and suggest that long-term immune activation by lysolipids may underlie both sporadic monoclonal gammopathies and Gaucher's disease-associated gammopathies (79). This work was built on genetic analyses over the past two decades of immunoglobulin mutations in MM cells that found myelomagenesis to be an antigen-driven process (80). Implications of these findings are that decreasing key lipids responsible for myeloma initiation potentially represents a novel preventative 
measure for at-risk populations. Moreover, the recent evidence finds that adipocyte-derived lipids, rather than adipokines, mediate obesity-related changes in macrophage phenotypes, highlighting the influential effects of adipocyte-derived lipids of the microenvironment (81).

Lipids also function as PPAR $\gamma$ agonists, and the PPAR $\gamma$ pathway has evident tumor-promoting properties in multiple cancers, as recently reviewed in Ref. (82) (Figures 3 and 4). Although the receptor-independent effects of PPAR $\gamma$ ligands compound our understanding of PPAR $\gamma$ in MM, the PPAR $\gamma$ agonist function of certain lipids likely creates a positive feedback loop both accelerating BM adipogenesis and directly supporting MM. Recent data have also found that the PPAR $\gamma$ agonist pioglitazone (PIO) enhances the cytotoxic effect of the histone deacetylase inhibitor (HDACi) and valproic acid (VPA) on MM cells, in vitro and in vivo, suggesting that agonizing PPAR $\gamma$ while inhibiting HDACs could decrease MM growth (83). Similarly, the PPAR $\gamma$ agonist rosiglitazone (RGZ) suppressed the expression of angiogenic factors in MM cells (HIF-1 $\alpha$ and IGF-1) and inhibited proliferation and reduced viability of RPMI-8226 cells in a concentration- and time-dependent manner (84). RGZ also inhibited the expression of pAKT and downregulated the expression levels of phosphorylated extracellular signal-regulated kinase (pERK) in MM cells (84). However, PPAR $\gamma$ has a strong osteoclastogenic effect that would likely worsen osteolysis for MM patients, highlighting a downside of using RGZ in MM.

In contrast to the above, the PGC- $1 \alpha$ is upregulated in myeloma cells grown in a high glucose media (modeling myeloma growth in hyperglycemic patients). It also contributes to chemotherapy (dexamethasone or bortezomib) resistance. These two properties suggest that inhibiting, rather than activating, the PPAR $\gamma$ pathway in MM cells (and controlling hyperglycemia) may improve the efficacy of chemotherapy in MM patients with diabetes. PGC- $1 \alpha$ also increases vascular endothelial growth factor gene (VEGF) and GLUT-4 expression in MM cells suggesting that inhibition of PGC- $1 \alpha$ in MM cells could decrease angiogenesis and glucose uptake, potentially slowing MM cell proliferation (85). Despite the growing knowledge in this area, it is still unclear how best to modulate the PPAR $\gamma$ pathway to inhibit MM disease progression in patients.

\section{Adipocyte Cell Signaling Pathways}

In addition to lipid molecules, there are a vast number of proteins derived from adipocytes that may influence MM tumor growth, as described here.

\section{Adipokine and Growth Factors Affecting MM Cells}

Adipocyte-derived cytokines (adipokines) within the local microenvironment may also uniquely stimulate the growth of MM cells or contribute to other aspects of the disease (86). Some of the major humoral factors and adipokines that WAT and BMAT secrete are TNF $\alpha$, monocyte chemoattractant protein-1 (MCP-1), plasminogen activator inhibitor-1 (PAI-1), resistin, leptin, and adiponectin $(87,88)$ (Figure 3 ). TNF $\alpha$ is a known MM-supportive, osteoclast-activating, and osteoblast-inhibitory factor (89). TNF $\alpha$ treatments induce MEK and AKT phosphorylation in MM cells and stimulate the production of IL-6. This causes a forward feedback loop that drives MM cell growth and survival (90). An autocrine TNF $\alpha$-MCP-1 loop has also been identified in MM cells, which was found to stimulate MM cell migration (91) (Figure 3).

Plasminogen activator inhibitor-1 causes increased risk of thrombosis, as it inhibits fibrinolysis, the physiological process that degrades blood clots (Figure 3). PAI-1 has been shown to be elevated in MM patients and appears to contribute to the greater risk of pulmonary embolism and blood clots in these patients (92). Some results suggest that patients with MM have decreased fibrinolytic activity mainly due to increased PAI-1 activity (92). In sum, these data suggest a link between adipocyte-specific cytokines, autocrine signaling, and obesity-linked cancer.

\section{Adipocyte-Derived Hormones}

Body weight is controlled by energy intake and expenditure, which are tightly regulated by communication between the brain and adipose depots through molecules such as adipocytederived hormones. Some hormones signal satiety (leptin) and represent high energy stores; others indicate hunger resulting from low blood glocose, inducing caloric intake as the hypothalamus receives these signals and regulates behavioral responses (93). Key adipokines such as adiponectin, leptin, and resistin are often present in skewed levels in various disease states (94-98). Abnormal adipokine levels and leptin-induced changes in gene expression profiles have been observed in MM, suggesting that these may be drivers or useful biomarkers of the disease (99-103).

\section{Adiponectin}

Adiponectin is an anti-inflammatory cytokine primarily produced by adipocytes but found to be secreted by additional cell types, including osteoblasts and BM MSCs (104). It is decreased in obesity (105-107) and has been shown to inhibit MM disease progression (100, 108) (Figure 4). In fact, low levels of adiponectin are associated with obesity, cardiovascular disease, and diabetes and are a risk factor for breast cancer (109). Circulating adiponectin was also decreased in patients with MGUS who then progressed to overt, symptomatic MM when compared to those with MGUS that did not develop MM (110). This study also showed that C57Bl6/KaLwRijHsd mice, which are permissive to $5 \mathrm{~T}$ murine myeloma cells, have significantly lower adiponectin gene expression and adiponectin protein in their BM and lower total serum adiponectin compared to the non-permissive, but closely related C57BL6/J mice (110). Moreover, pharmacological stimulation of adiponectin in tumor-bearing miceled to a decrease in tumor burden and increased survival (110). Importantly, in humans, low circulating adiponectin and resistin, but not leptin, are associated with MM $(99,100,108)$. Adiponectin has been shown to inhibit proliferation of MM through an increase in cell death via activation of the protein kinase A/AMP-activated pathways (111) (Figure 4). In sum, these are important findings that demonstrate the potential relevance of increasing adiponectin for MM and associated bone disease therapy.

Bone marrow adipose tissue, WAT, and BAT-derived adipocytes express relatively similar amounts of the anti-myeloma protein adiponectin on the mRNA level (40), but on the protein 
level, and in vivo, adiponectin secretion is greater from MAT than from WAT (42). Moreover, BMAT specifically increases its production of adiponectin in times of starvation and in patients with cancer therapy (42). Expression of adipoq, the gene encoding adiponectin, in tibiae and femurs has been found to mirror changes in serum adiponectin, which suggests that circulating adiponectin levels are directly related to adiponectin production from BMAT (42). Therefore, adiponectin appears to be one of the major BMAT-derived molecules responsible for signaling from BMAT to MM cells.

\section{Leptin}

Leptin, a peptide hormone produced and secreted by adipocytes, has primarily been characterized for its role in the regulation of hunger response and metabolic activity (112). The main signaling capability of leptin is through the long form of its receptor, which is expressed in peripheral and brain tissues, although its primary function has been identified as signaling through the hypothalamus (112). Signaling through its receptor, leptin stimulates JAK/ STAT cascades, mainly JAK2/STAT3 and JAK2/STAT5, to signal satiety (Figure 3). Congenital leptin deficiency in both mice and humans results in early obesity due to severe hyperphagia, but can be corrected with leptin replacement therapies $(113,114)$. In patients with obesity, circulating leptin levels are significantly higher than in normal age- and sex-matched patients, suggesting that a level of leptin resistance exists in these obese patients (115). Plasma leptin levels were found to be increased in both newly diagnosed male and female MM patients compared to healthy controls (100), and leptin levels are decreased in response to disease treatment (102). Similar to the effects of lipids mentioned above, autophagy, can also be induced by adipocyte-derived hormones (116) (Figure 3). Adipocytes have been found to upregulate the expression of autophagic proteins in MM cells via leptin and adipsin, leading to chemoresistance, suppression of caspase cleavage, and suppression of apoptosis in melphalan-treated MM cells in vitro and in vivo (67).

Resistin, Insulin, Insulin-Like Growth Factor 1, and Androgens Data on resistin do not translate as well from mice to human as leptin appears to, and the relationship between resistin and adiposity is not consistent between humans and mice (117).

Still, in both species, resistin is elevated in obesity, regulates insulin sensitivity, and is positively associated with insulin resistance and glucose tolerance (118). In clinical studies, low circulating resistin levels are associated with MM risk (108). Yet, another study found no significant differences in circulating serum resistin levels between newly diagnosed MM patients and healthy controls (100). Insulin and IGF-1 are, however, both adipose-derived growth factors that stimulate proliferation for MM cells $(68,119)$ (Figure 3). Lastly, adipose tissue is one of the major sources of aromatase, an enzyme also expressed in the gonads, which synthesizes estrogens from androgen precursors. Adipose-derived aromatase and the subsequent synthesis of estrogen could contribute to MM growth, as certain MM cells have been found to express estrogen receptors and proliferate in response to estrogen (78). However, the bone anabolic effects of estrogen suggest that this enzyme could combat myelomainduced bone disease. In sum, the net effects that adipocytederived hormones potentiate on MM and MM-induced bone disease are currently an open area of research.

\section{BMAT and Hypoxia: Tumor Growth and Drug Resistance}

The relationship between BMAT and hypoxia is likely an important, dynamic, and bidirectional relationship that contributes to MM development and drug resistance. As oxygen tension ranges from 21 (in normoxia) to $12 \%$ in peripheral blood and $~ 1.3$ to $3 \%$ (hypoxia) in the BM, based on the proximity to the vasculature and endosteum (120), it is probable that BMAT-MM in vitro experiments, and perhaps all BM cultures, will give more translational data if they are performed in hypoxic rather normoxic conditions (121). This is because hypoxia can drive proliferation of stem cells via HIF1 signaling (122), induce drug resistance in MM cells, and affect MM cell homing and egress from the BM (123-126). Some data demonstrate that hypoxia decreases adipogenic differentiation (127), and severe hypoxia $\left(1 \% \mathrm{O}_{2}\right)$ inhibits adipogenic, chondrogenic, and osteogenic differentiation of human BM-MSCs (128). Pachón-Peña et al. found that hypoxia increased adipose-derived stem cell (hASC) proliferation and migration from lean, but not obese, patients (129), so patient type is likely important in how cells respond to hypoxia. hASC donor BMI has also been found to dictate adipogenic potential, immunophenotypic profile, and response to oxygen tension in vitro (129). Other studies have confirmed that obesity, and FFAs specifically, decrease stem cell multipotency (130). Overall, there appears to be an interaction coefficient between donor $\mathrm{BMI} /$ lipids and response to hypoxia for stem cells, suggesting that multiparameter experiments should be designed to capture these complex, non-linear interactions.

Hypoxia itself is an important factor in tumor drug resistance and is associated with poor prognosis. However, due to the challenges associated with measuring oxygen tension within the $\mathrm{BM}$, it is not yet clear how, or if, the oxygen gradients in the BM specifically dictate the locations of osteolysis (131). Hypoxia activates the VEGF (132), a major stimulator of angiogenesis and neovascularization, as well as a direct inducer of MM cell growth, survival, and migration (133). Neovascularization is common in the bones of myeloma patient and in mice in areas infiltrated with myeloma cells and provides more exit routes for tumor cell intravasation and increased nutrient delivery to sustain tumor growth (134). Targeting vasculogenesis and VEGF signaling has been found to be successful to decrease tumor burden in in vivo models (25). VEGF concentration in the BM significantly correlates with BM microvascular density, percentage of tumor cells in bone biopsy, and hypercalcemia (135). VEGF is also significantly increased in patients after treatment who progress versus those with a partial or complete remission (135). Since adipose tissue has been shown to express high levels of VEGF, it is likely that BMAT is an important source for VEGF family members in the BM, supporting aberrant microvessel growth and neovascularization and directly fueling MM cell proliferation $(136,137)$. Paracrine signaling of VEGFA from BMAT to MM 
cells may also be fueled through autocrine signaling, as MM cells also demonstrate high VEGFA expression and production levels (124).

As MM cells are often resistant to hypoxia-induced cell death, antiangiogenic factors do not seem to be highly effective for this type of tumor cell, despite the correlations between BM vessels and disease progression. Hypoxia protects tumor cells from apoptosis through an increase in local VEGF concentrations and subsequent increases in tumor cell MAPK/ERK signaling (138). In MM cells, hypoxia increases HIF1 $\alpha$ and activates the PI3K/ Akt/mammalian target protein of rapamycin (mTOR) pathway (139). MM cells in the BM also show high glucose uptake, similar to most tumors, as demonstrated by 18 F-FDG PET imaging and increased glucose transport protein 3 (GLUT3) expression (140). As the metabolic shift from oxidative metabolism to glycolysis occurs based on both energy and oxygen sources, it is clear that the fuel type (lipid versus glucose), expression of glucose transporter, and glycolytic enzymes, as well as oxygen tension, direct tumor cell metabolism and fuel switching. Therefore, lipids and adipose tissue affect MM cell metabolism depending on oxygen availability. Specifically, decreasing local lipid concentrations may simply switch tumor cell metabolism from fatty-acid oxidation to glycolysis and not necessarily decrease tumor proliferation, or, fuel switching coupled with oxygen tension control may prove a viable therapeutic avenue through which to tackle MM. As a final consideration here, intermittent hypoxia also affects adipose tissue macrophage polarization and tumor infiltration, suggesting that immune changes should also be considered when investigating metabolic and hypoxic-based interventions in MM (141).

\section{Bone Marrow Adipocytes and Skeletal Remodeling}

The growing evidence associating elevated BMAT with low bone density suggests that BM adipocytes may contribute to bone loss in MM or that bone loss may contribute to increased BM adiposity. Either dynamic could support MM growth and increased risk of fracture (Figure 2). In humans (142-145) and rodents (146-149), there is often an inverse correlation between BMAT and bone quantity. Decreased bone volume or mass coinciding with higher BMAT is consistently observed across sexes, ages, models, and underlying disease etiologies (54). Moreover, many pharmacologic strategies cause opposing effects on bone and adipose tissue [glucocorticoids, hormone replacement therapies, radiation, and thiazolidinediones (TZD)] (150). Higher BMAT has been found to correlate with lower trabecular bone mineral density (BMD) in older women, but not men, and higher marrow fat is associated with prevalent vertebral fracture in men, even after adjustment for BMD (145). Lumbar spine BMD has been found to negatively correlate with BMAT (151). High BMAT also leads to disrupted hematopoiesis and reduced $\mathrm{BMD}$ in other studies and may increase the risk of bone metastasis, potentially resulting from an increase in receptor activator of NFKB-ligand (RANKL) and downregulation of osteoprotegerin, as observed in aging-related marrow adipogenesis $(44,152,153)$.
In moving beyond correlation into causation, recent evidence demonstrates that adipocytes actively inhibit osteogenesis, based on lower mineralization, alkaline phosphatase activity, and expression of osteogenic (Runx2, osteocalcin) mRNA markers, using conditioned media experiments with hMSCs (154). Adipocytes can also induce osteoblast apoptosis (154). One pathway found to govern the effects of adipokines on osteoblasts is the PI3-kinaseFoxO1 pathway (155). Both decreased osteoblast function and induced apoptosis were enhanced by dexamethasone treatment of adipocytes, and both processes appear to be driven by the lipotoxic effect of two FFAs, stearate and palmitate, which may act as PPAR $\gamma$-ligands (inhibiting osteogenesis), and can induce ROS in human cells (154). These findings demonstrate that increased BMAT may decrease osteogenesis, thus contributing to bone disease in MM patients, although this has not yet been explored in myeloma patient MSCs. Overall, the effects of BMAT specifically on MM-induced bone disease and osteolysis may be substantial and promising as a new therapeutic target.

\section{Bone Marrow Adipocytes and Hematopoiesis}

As BM adipocytes are interspersed throughout the vascular and endosteal niches responsible for guiding the lineage commitment of HSCs, they may also affect hematopoiesis both via local and systemic effects. Research on human iliac crest-derived marrow adipocytes found that these cells have the ability to support CD $34^{+}$hematopoietic progenitor cells in vitro (39). BMAT is also intimately associated with the blood-forming marrow. Primary human BMAT adipocytes, purified from the iliac crest, have the ability to support differentiation of $\mathrm{CD} 34^{+}$hematopoietic progenitor cells in long-term culture in vitro (39). Yet, other data suggest that BMAT may be inhibitory toward hematopoiesis; this has been observed in mouse experiments where BMAT induced hematopoietic cell quiescence and decreased the number of progenitor marrow cells (51). Adipocyte-derived factors are also known to inhibit B lymphopoiesis (156).

The number of adult BM adipocytes was found to correlate inversely with the hematopoietic activity of the marrow and decrease marrow transplant cell engraftment after irradiation (51). Yet, in another study, mice treated with a TZD called "Troglitazone," which causes massive BMAT expansion, hematopoietic progenitor frequency was not altered, and, in fact, preadipocytes were found to support hematopoetic cells in vitro (77). Thus, it is unclear if MAT always has a negative influence on the hematopoietic niche, or if this is time, location, or disease dependent.

\section{INFLUENCES OF MYELOMA ON BMAT}

Bone marrow MSCs can give rise to BM adipocytes and osteoblasts, as dictated through expression of proteins in major transcriptional regulatory pathways such as PPAR $\gamma$ and Wnt, respectively. It is not well understood how MM cells alter BMAT or MSC cell fate, but a study from 2007 revealed that MM-MSCs retain their capacity to differentiate down adipogenic and osteogenic lineages, although quantification of this differentiation 
(e.g., with oil red $\mathrm{O}$ or alizarin red staining) was not performed (157). Studies since then have observed a decreased ability for MM-MSCs to proliferate and undergo osteogenic differentiation $(5,32)$, suggesting that their adipogenic capacity may be altered. It is also possible that MM cells utilize the lipids stored in BMAT to fuel their proliferation and migration, as other tumor cells (ovarian cells) have been found to do in other adipose depots (the omentum) (158). This utilization would decrease the amount of lipid stored in these cells, though this is an observation that has yet to be examined. Research into the bidirectional communication between MM cells and BMAT is needed to determine how MM cells affect BMAT as well as the ramifications of these interactions on tumor growth and osteolysis.

\section{LINKING BMAT AND SYSTEMIC INFLAMMATION}

Bone marrow adipose tissue is linked to systemic inflammation through mechanisms that include the production of proinflammatory cytokines and lipids able to undergo oxidation. Obesity and aging both correlate with increased systemic inflammation, increased risk of MM, and increased BMAT. This leads to a few potential hypotheses: (1) that BMAT drives MM through local and/or systemic effects (e.g., on inflammation), or (2) that elevated BMAT and MM correlate because both are driven by a common or linked underlying mechanism, e.g., obesity, aging, or decreased immune function. Currently, either hypothesis could prove true. While WAT imparts systemic/endocrine influences, BMAT may produce systemic as well as local, paracrine, and cell-cell contact-based effects on tumors. The close proximity of BMAT and MM cells suggests potential contact-mediated bidirectional signaling between these cells, which is absent from WAT-MM cell interactions. However, WAT appears to be comprised of cells that derive from the marrow (up to 35\%) (159); the signaling parallels and lineage tracing links between WAT and BMAT confound determining the specific contributions of each toward MM progression or myelomagenesis. Although more research examining the specific contributions of each depot are needed, much evidence suggests that immune system alterations resulting from elevated BMAT or WAT could contribute to MM progression $(44,152,160)$.

In breast cancer, obesity-related host factors, such as components of the secretome (e.g., insulin, IGF-1, leptin, adiponectin, steroid hormones, cytokines, vascular regulators, and inflammationrelated molecules), explain the causative link between increased risk of breast cancer in postmenopausal women and poor prognosis in pre- and postmenopausal women (161). Many of these same factors are also systemic signals that could explain the link between obesity and increased MM risk. However, proinflammatory cytokines that are derived from adipose tissue, such as IL-1 (162), can be difficult to identify as anti-myeloma or myelomasupportive, because of the complex roles of the immune system in cancer. In general, immune cells attack and can eliminate myeloma cells. But systemic inflammation can also contribute to tumor growth if regulatory T-cells or myeloid suppressor cells (which are cells that suppress other immune cells) are increased. Other adipocyte-derived factors are proinflammatory and support natural killer cells, such as IL-15 (163). As genetically modified, exvivo-expanded natural killer cells are being used as a treatment for MM and many cancers, IL-15 and adipocyte-induced support of NK cells may in fact have anti-myeloma consequences (164). Yet, IL-15, along with other angiogenic factors (VEGF, IL-6, and HGF), is also significantly increased in MM patient blood serum reflecting a correlation between angiogenesis and MM (164). From this perspective, IL-15 and these other adipocytederived factors appear to support tumor growth through both direct effects and also increased tumor vascularization. MSC adipogenic differentiation has also been found to be modulated by natural killer cells (165), suggesting that a forward feedback loop between inflammation and adipogenesis may be at work. These data suggest that adipocytes not only are affected by, but also affect, the immune system. For a review on systemic and BMAT-induced inflammation and its contributions to tumor growth and survival, dysregulated bone remodeling, and activation of inflammatory pathways in tumor cells (e.g., CCL2/ CCR2- and COX-2-dependent pathways), refer to the review by Hardaway et al. (166).

Lipids are essential components of cell membranes and represent an energy-rich fuel source. However, lipids are frequently targeted by reactive oxygen species (ROS), such as free radicals. This leads to the oxidation of lipids in a chain reaction known as lipid peroxidation, which has been associated with a wide range of diseases, including cancer, diabetes, and neurological disorders (167). Many of the products of free radical chain oxidation are unstable, but stable isoprostanes have become the gold standard measurable biomarker for oxidative stress (167). One well-studied lipid electrophile, 4-NHE, is generated from lipid peroxidation and mediates a variety of biological processes (e.g., DNA damage, mutagenesis, inflammatory response, cell growth, and apoptosis) through a range of pathways (ER stress, stress-responsive MAP kinase signaling, NF-kB signaling, and DNA damage response signaling) (167). Malondialdehyde (MDA) is another product of lipid peroxidation; it is highly mutagenic (168). MDA and 4-NHE are two molecules responsible for lipid-initiated genetic disruption that could support MM development through numerous pathways, such as the oxidative stress-driven activation of the PI3K/AKT pathway and inactivation of the tumor suppressor gene PTEN (169). Oxidative stress can also lead to increased PPAR, Cox-2, MAPK, and PKC signaling; any of these pathways could support myelomagenesis or disease progression (170). As antioxidants can abrogate oxidative-stress-induced apoptosis of osteoblasts, they may represent a potential therapeutic avenue in MM (154).

\section{TREATMENTS TARGETING BMAT}

There is immense potential in targeting BMAT or BMATderived factors, to combat myeloma initiation, progression, relapse, chemoresistance, and osteolysis. Based on preclinical data regarding the roles of adiponectin in MM, recombinant or biologically isolated adiponectin treatment for MM patients with low adiponectin levels may hold great potential as a therapeutic treatment. Similarly, decreasing BMAT-derived factors that are MM-supportive using inhibitors or antibodies may be a potential 
future BMAT-targeted therapy. Another way to target BMAT may be to target those signaling pathways that push MSCs down the adipogenic rather than osteogenic lineage, thus flipping the commitment lineage switch. One such pathway is the Wnt signaling pathway, which supports osteogenic differentiation and inhibits adipogenic differentiation. As we know that sclerostin, a Wnt inhibitor, is elevated in the BM of MM patients, it is possible that antisclerostin antibodies would not only increase bone volumes but also decrease BMAT in MM patient marrow, creating a less hospitable microenvironment for MM cells to colonize (171, 172). Other potential target lineage switches that induce osteogenesis and limit adipogenesis are parathyroid hormone receptor (PTH), TAZ/YAP (173), and numerous zinc finger proteins (174).

It is important to consider the link between BMAT and bone when analyzing adipose-directed therapies, because treatments that affect bone could affect BMAT (and vice versa). As there appears to be a reciprocal relationship between BMAT and bone formation in both healthy and diseased conditions (175, 176), increasing bone mass may be one novel way to decrease BMAT and also strengthen bones that are weakened by MM. It is becoming clear that the skeleton has a complex, non-linear, and genotype-dependent relationship with energy utilization and MAT $(151,177)$. Exercise has been shown to significantly suppress BMAT volume and induce bone formation in certain mouse models, suggesting that a healthy diet and increased exercise or strength training program could create a two-pronged attack to strengthen bones and decrease BMAT in MGUS or MM patients (178). The antidiabetic drug metformin can also decrease BMAT in mice that are fed with a high fat diet (Michaela R. Reagan and CJ Rosen, unpublished data). It can also modestly improve bone volume (179) as well as directly affect metabolism of tumor cells (180). These data suggest that metformin may be another potential multidimensional therapeutic. The topic of metformin effects on cancer has been reviewed recently (181).

Altering lipid levels, ratios, or content systemically or in the BM may also hold great promise as an anti-myeloma treatment. For instance, Abdi et al. demonstrated that omega-3 fatty acids [n-3 polyunsaturated eicosapentaenoic acid (EPA) and docosahexaenoic acid (DHA)] induced apoptosis and increased sensitivity to bortezomib in MM cells preclinically, without affecting normal human peripheral mononuclear cells viability (182). These lipids modulated multiple signaling pathways including NFkB, Notch, Hedgehog, oxidative stress, and Wnt. They also induced apoptosis through mitochondrial perturbation and caspase- 3 activation (182). Combined with the data above on oxidative stress, these data suggest that supplements such as vitamins (antioxidants) and fish oil, and/or diets rich in fish, fruits, and vegetables, should be explored as preventative measures in the development of MM. However, carefully designed trials are necessary to best optimize treatment regimes, as some antioxidants, such as vitamin $\mathrm{C}$ and flavonoids in vegetables, fruits, and green tea, can neutralize and should not

\section{REFERENCES}

1. Hanahan D, Weinberg RA. The hallmarks of cancer. Cell (2000) 100:57-70. doi:10.1016/S0092-8674(00)81683-9 be used with bortezomib, a commonly prescribed anti-myeloma proteasome inhibitor (183).

\section{CONCLUSION}

As reviewed herein, BMAT appears to affect MM through an array of different mechanisms. We have described what is currently understood about the BM adipocyte and BMAT. We next highlighted the ways in which BMAT may support MM, for example, through bioactive lipids (as a fuel source, signaling molecule, and a substrate for lipid peroxidation), and myelomasupportive adipokines (e.g., IL-6, TNF $\alpha$, MCP-1, PAI-1, IL-6, resistin, and leptin). We also provided an overview of adiponectin, a protein that is decreased during obesity and has anti-myeloma properties making it an attractive potential therapeutic in MM. The complex relationship between hypoxia, BMAT, angiogenesis, and myeloma in the BM was discussed. Influence of BMAT on bone health and osteogenesis was delineated, and our current understandings of potential ways in which MM cells may affect BMAT were outlined. The review investigates the relationship between BMAT and systemic inflammation in relation to MM. Lastly, we suggested possible therapeutic avenues through which BMAT could be targeted, similarly to how osteoblasts and osteoclasts, and factors derived from these cells, have been successfully targeted in MM. Targeting lipid metabolism of cancer cells and adipocytes in combination with standard antimyeloma therapies will likely reveal novel therapeutic avenues through which to attack hematological malignancies. In sum, we are optimistic about the development of new combination therapies and preventative methods that take into account the roles of the BM adipocyte in MM and other bone-metastatic cancers. The path toward improved therapies will be built on basic scientific research of BMAT roles in cancer.

\section{AUTHOR CONTRIBUTIONS}

$\mathrm{CF}, \mathrm{HF}$, and MR contributed to the conception, drafting, writing, and editing of this work.

\section{ACKNOWLEDGMENTS}

The authors thank Dr. Michael Erard, Scientific Editor and Writing consultant at Maine Medical Center Research Institute (MMCRI) for editorial assistance. We apologize to colleagues whose work could not be cited due to space constraints.

\section{FUNDING}

The authors' work is supported by Start-up funds, a pilot project grant and support from NIH/NIGMS (P30 GM106391 and P30GM103392), and the NIH/NIDDK (R24 DK092759-01) at Maine Medical Center Research Institute.

2. Hanahan D, Weinberg RA. Hallmarks of cancer: the next generation. Cell (2011) 144:646-74. doi:10.1016/j.cell.2011.02.013

3. Palumbo A, Anderson K. Multiple myeloma. N Engl J Med (2011) 364: 1046-60. doi:10.1056/NEJMra1011442 
4. Fairfield H, Falank C, Avery L, Reagan MR. Multiple myeloma in the marrow: pathogenesis and treatments. Ann N Y Acad Sci (2016) 1364:32-51. doi:10.1111/nyas. 13038

5. Reagan MR, Ghobrial IM. Multiple myeloma-mesenchymal stem cells: characterization, origin, and tumor-promoting effects. Clin Cancer Res (2012) 18:342-9. doi:10.1158/1078-0432.CCR-11-2212

6. Kawano Y, Moschetta M, Manier S, Glavey S, Görgün GT, Roccaro AM, et al. Targeting the bone marrow microenvironment in multiple myeloma. Immunol Rev (2015) 263:160-72. doi:10.1111/imr.12233

7. Alexander DD, Mink PJ, Adami H-O, Cole P, Mandel JS, Oken MM, et al. Multiple myeloma: a review of the epidemiologic literature. Int J Cancer (2007) 120(Suppl):40-61. doi:10.1002/ijc.22718

8. Palumbo A, Avet-Loiseau H, Oliva S, Lokhorst HM, Goldschmidt H, Rosinol L, et al. Revised international staging system for multiple myeloma: a report from international myeloma working group. J Clin Oncol (2015) 33:2863-9. doi:10.1200/JCO.2015.61.2267

9. Wright JH. A case of multiple myeloma. JBoston Soc Med Sci (1900) 4:195-204.5.

10. Teras LR, Kitahara CM, Birmann BM, Hartge PA, Wang SS, Robien K, et al. Body size and multiple myeloma mortality: a pooled analysis of 20 prospective studies. Br J Haematol (2014) 166:667-76. doi:10.1111/bjh.12935

11. Qian H, Buza-Vidas N, Hyland CD, Jensen CT, Antonchuk J, Månsson R, et al. Critical role of thrombopoietin in maintaining adult quiescent hematopoietic stem cells. Cell Stem Cell (2007) 1:671-84. doi:10.1016/j.stem.2007.10.008

12. Lohr JG, Stojanov P, Carter SL, Cruz-Gordillo P, Lawrence MS, Auclair D, et al. Widespread genetic heterogeneity in multiple myeloma: implications for targeted therapy. Cancer Cell (2014) 25:91-101. doi:10.1016/j.ccr.2013.12.015

13. Sahin I, Azab F, Mishima Y, Moschetta M, Tsang B, Glavey SV, et al. Targeting survival and cell trafficking in multiple myeloma and Waldenstrom macroglobulinemia using pan-class I PI3K inhibitor, buparlisib. Am J Hematol (2014) 89:1030-6. doi:10.1002/ajh.23814

14. Brunetti G, Rizzi R, Oranger A, Gigante I, Mori G, Taurino G, et al. LIGHT/TNFSF14 increases osteoclastogenesis and decreases osteoblastogenesis in multiple myeloma-bone disease. Oncotarget (2014) 5:12950-67. doi:10.18632/oncotarget.2633

15. Suen H, Brown R, Yang S, Weatherburn C, Ho PJ, Woodland N, et al. Multiple myeloma causes clonal T-cell immunosenescence: identification of potential novel targets for promoting tumour immunity and implications for checkpoint blockade. Leukemia (2016). doi:10.1038/leu.2016.84

16. Fu J, Li S, Feng R, Ma H, Sabeh F, Roodman GD, et al. Multiple myeloma-derived MMP-13 mediates osteoclast fusogenesis and osteolytic disease. J Clin Invest (2016) 126:1759-72. doi:10.1172/JCI80276

17. Colucci S, Brunetti G, Mori G, Oranger A, Centonze M, Mori C, et al. Soluble decoy receptor 3 modulates the survival and formation of osteoclasts from multiple myeloma bone disease patients. Leukemia (2009) 23:2139-46. doi:10.1038/leu.2009.136

18. Reagan MR, Liaw L, Rosen CJ, Ghobrial IM. Dynamic interplay between bone and multiple myeloma: emerging roles of the osteoblast. Bone (2015) 75:161-9. doi:10.1016/j.bone.2015.02.021

19. Palma BD, Guasco D, Pedrazzoni M, Bolzoni M, Accardi F, Costa F, et al. Osteolytic lesions, cytogenetic features and bone marrow levels of cytokines and chemokines in multiple myeloma patients: role of chemokine (C-C motif) ligand 20. Leukemia (2016) 30:409-16. doi:10.1038/leu.2015.259

20. Raje N, Vadhan-Raj S, Willenbacher W, Terpos E, Hungria V, Spencer A, et al. Evaluating results from the multiple myeloma patient subset treated with denosumab or zoledronic acid in a randomized phase 3 trial. Blood Cancer $J$ (2016) 6:e378. doi:10.1038/bcj.2015.96

21. Croucher PI, McDonald MM, Martin TJ. Bone metastasis: the importance of the neighbourhood. Nat Rev Cancer (2016) 16:373-86. doi:10.1038/nrc. 2016.44

22. Vanderkerken K, De Leenheer E, Shipman C, Asosingh K, Willems A, Van Camp B, et al. Recombinant osteoprotegerin decreases tumor burden and increases survival in a murine model of multiple myeloma. Cancer Res (2003) 63:287-9.

23. Swami A, Reagan MR, Basto P, Mishima Y, Kamaly N, Glavey S, et al. Engineered nanomedicine for myeloma and bone microenvironment targeting. Proc Natl Acad Sci U S A (2014) 111:10287-92. doi:10.1073/ pnas. 1401337111
24. Lawson MA, McDonald MM, Kovacic NN, Hua Khoo W, Terry RTL, Down J, et al. Osteoclasts control re-activation of dormant myeloma cells by remodeling the endosteal niche. Nat Commun (2015) 6:8983. doi:10.1038/ ncomms 9983

25. Moschetta M, Mishima Y, Kawano Y, Manier S, Paiva B, Palomera L, et al. Targeting vasculogenesis to prevent progression in multiple myeloma. Leukemia (2016) 30:1103-15. doi:10.1038/leu.2016.3

26. Moschetta M, Mishima Y, Sahin I, Manier S, Glavey S, Vacca A, et al. Role of endothelial progenitor cells in cancer progression. Biochim Biophys Acta (2014) 1846:26-39. doi:10.1016/j.bbcan.2014.03.005

27. Glavey SV, Huynh D, Reagan MR, Manier S, Moschetta M, Kawano Y, et al. The cancer glycome: carbohydrates as mediators of metastasis. Blood Rev (2015) 29:269-79. doi:10.1016/j.blre.2015.01.003

28. Glavey SV, Manier S, Natoni A, Sacco A, Moschetta M, Reagan MR, et al. The sialyltransferase ST3GAL6 influences homing and survival in multiple myeloma.Blood(2014) 124(11):1765-76. doi:10.1182/blood-2014-03-560862

29. Azab AK, Quang P, Azab F, Pitsillides C, Thompson B, Chonghaile T, et al. P-selectin glycoprotein ligand regulates the interaction of multiple myeloma cells with the bone marrow microenvironment. Blood (2011) 119:1468-78. doi:10.1182/blood-2011-07-368050

30. Roccaro AM, Sacco A, Purschke WG, Moschetta M, Buchner K, Maasch C, et al. SDF-1 inhibition targets the bone marrow niche for cancer therapy. Cell Rep (2014) 9:118-28. doi:10.1016/j.celrep.2014.08.042

31. Azab AK, Runnels JM, Pitsillides C, Moreau A-S, Azab F, Leleu X, et al. CXCR4 inhibitor AMD3100 disrupts the interaction of multiple myeloma cells with the bone marrow microenvironment and enhances their sensitivity to therapy. Blood (2009) 113:4341-51. doi:10.1182/blood-2008-10-186668

32. Reagan MR, Mishima Y, Glavey SV, Zhang Y, Manier S, Lu ZN, et al. Investigating osteogenic differentiation in multiple myeloma using a novel 3D bone marrow niche model. Blood (2014) 124:3250-9. doi:10.1182/ blood-2014-02-558007

33. Roccaro AM, Sacco A, Maiso P, Azab AK, Tai Y-T, Reagan M, et al. BM mesenchymal stromal cell-derived exosomes facilitate multiple myeloma progression. J Clin Invest (2013) 123:1542-55. doi:10.1172/JCI66517

34. Manni S, Toscani D, Mandato E, Brancalion A, Quotti Tubi L, Macaccaro P, et al. Bone marrow stromal cell-fueled multiple myeloma growth and osteoclastogenesis are sustained by protein kinase CK2. Leukemia (2014) 28:2094-7. doi:10.1038/leu.2014.178

35. Delgado-Calle J, Anderson J, Cregor MD, Hiasa M, Chirgwin JM, Carlesso $\mathrm{N}$, et al. Bidirectional Notch signaling and osteocyte-derived factors in the bone marrow microenvironment promote tumor cell proliferation and bone destruction in multiple myeloma. Cancer Res (2016) 76:1089-100. doi:10.1158/0008-5472.CAN-15-1703

36. Colaianni G, Colucci S, Grano M. 1st ed. In: Lenzi A, Migliaccio S, Maria Donini L, editors. Multidisciplinary Approach to Obesity: From Assessment to Treatment. Switzerland: Springer International Publishing (2015). Available from: http://www.springer.com/us/book/9783319090443

37. Scheller EL, Rosen CJ. What's the matter with MAT? Marrow adipose tissue, metabolism, and skeletal health. Ann N Y Acad Sci (2014) 1311:14-30. doi: $10.1111 /$ nyas. 12327

38. Lecka-Czernik B. Marrow fat metabolism is linked to the systemic energy metabolism. Bone (2012) 50:534-9. doi:10.1016/j.bone.2011.06.032

39. Poloni A, Maurizi G, Serrani F, Mancini S, Zingaretti MC, Frontini A, et al. Molecular and functional characterization of human bone marrow adipocytes. Exp Hematol (2013) 41:558-566.e2. doi:10.1016/j.exphem.2013.02.005

40. Lecka-Czernik B, Stechschulte LA. Bone and fat: a relationship of different shades. Arch Biochem Biophys (2014) 561:124-9. doi:10.1016/j. abb.2014.06.010

41. Devlin MJ, Cloutier AM, Thomas NA, Panus DA, Lotinun S, Pinz I, et al. Caloric restriction leads to high marrow adiposity and low bone mass in growing mice. J Bone Miner Res (2010) 25:2078-88. doi:10.1002/jbmr.82

42. Cawthorn WP, Scheller EL, Learman BS, Parlee SD, Simon BR, Mori H, et al. Bone marrow adipose tissue is an endocrine organ that contributes to increased circulating adiponectin during caloric restriction. Cell Metab (2014) 20:368-75. doi:10.1016/j.cmet.2014.06.003

43. Xuan D, Han Q, Tu Q, Zhang L, Yu L, Murry D, et al. Epigenetic modulation in periodontitis: interaction of adiponectin and JMJD3-IRF4 axis in macrophages. J Cell Physiol (2016) 231:1090-6. doi:10.1002/jcp.25201 
44. Adler BJ, Kaushansky K, Rubin CT. Obesity-driven disruption of haematopoiesis and the bone marrow niche. Nat Rev Endocrinol (2014) 10:737-48. doi:10.1038/nrendo.2014.169

45. Doucette CR, Horowitz MC, Berry R, MacDougald OA, Anunciado-Koza R, Koza RA, et al. A high fat diet increases bone marrow adipose tissue (MAT) but does not alter trabecular or cortical bone mass in C57BL/6J mice. J Cell Physiol (2015) 230(9):2032-7. doi:10.1002/jcp.24954

46. Scheller EL, Cawthorn WP, Burr AA, Horowitz MC, MacDougald OA. Marrow adipose tissue: trimming the fat. Trends Endocrinol Metab (2016) 27:392-403. doi:10.1016/j.tem.2016.03.016

47. Scheller EL, Troiano N, Vanhoutan JN, Bouxsein MA, Fretz JA, Xi Y, et al. Use of osmium tetroxide staining with microcomputerized tomography to visualize and quantify bone marrow adipose tissue in vivo. Methods Enzymol (2014) 537:123-39. doi:10.1016/B978-0-12-411619-1.00007-0

48. Bredella MA, Lin E, Gerweck AV, Landa MG, Thomas BJ, Torriani M, et al. Determinants of bone microarchitecture and mechanical properties in obese men. J Clin Endocrinol Metab (2012) 97:4115-22. doi:10.1210/jc.2012-2246

49. MiyakoshiN,Sato K, Abe T, Tsuchida T, Tamura Y,Kudo T. Histomorphometric evaluation of the effects of ovariectomy on bone turnover in rat caudal vertebrae. Calcif Tissue Int (1999) 64:318-24. doi:10.1007/s002239900626

50. LiM, Shen Y,QiH, WronskiTJ. Comparative study of skeletal response to estrogendepletionatredandyellow marrowsitesin rats. Anat Rec (1996) 245:472-80. doi:10.1002/(SICI)1097-0185(199607)245:3<472:AID-AR3>3.0.CO;2-U

51. Naveiras O, Nardi V, Wenzel PL, Hauschka PV, Fahey F, Daley GQ. Bonemarrow adipocytes as negative regulators of the haematopoietic microenvironment. Nature (2009) 460:259-63. doi:10.1038/nature08099

52. Bornstein S, Brown SA, Le PT, Wang X, DeMambro V, Horowitz MC, et al. FGF-21 and skeletal remodeling during and after lactation in C57BL6 mice. Endocrinology (2014) 155:3516-26. doi:10.1210/en.2014-1083

53. Ackert-Bicknell CL, Shockley KR, Horton LG, Lecka-Czernik B, Churchill GA, Rosen CJ. Strain-specific effects of rosiglitazone on bone mass, body composition, and serum insulin-like growth factor-I. Endocrinology (2009) 150:1330-40. doi:10.1210/en.2008-0936

54. Reagan MR, Rosen CJ. Navigating the bone marrow niche: translational insights and cancer-driven dysfunction. Nat Rev Rheumatol (2015) 12:154-68. doi:10.1038/nrrheum.2015.160

55. Rosen CJ, Ackert-Bicknell C, Rodriguez JP, Pino AM. Marrow fat and the bone microenvironment: developmental, functional, and pathological implications. Crit Rev Eukaryot Gene Expr (2009) 19:109-24. doi:10.1016/j. bbi.2008.05.010

56. Fazeli PK, Horowitz MC, MacDougald OA, Scheller EL, Rodeheffer MS, Rosen CJ, et al. Marrow fat and bone-new perspectives. J Clin Endocrinol Metab (2013) 98:935-45. doi:10.1210/jc.2012-3634

57. Roura S, Farré J, Soler-Botija C, Llach A, Hove-Madsen L, Cairó JJ, et al. Effect of aging on the pluripotential capacity of human CD105+ mesenchymal stem cells. Eur J Heart Fail (2006) 8:555-63. doi:10.1016/j.ejheart.2005.11.006

58. Kretlow JD, Jin Y-Q, Liu W, Zhang WJ, Hong T-H, Zhou G, et al. Donor age and cell passage affects differentiation potential of murine bone marrow-derived stem cells. BMC Cell Biol (2008) 9:60. doi:10.1186/1471-2121-9-60

59. Maredziak M, Marycz K, Tomaszewski KA, Kornicka K, Henry BM. The influence of aging on the regenerative potential of human adipose derived mesenchymal stem cells. Stem Cells Int (2016) 2016:1-15. doi:10.1155/2016/2152435

60. Singh L, Brennan TA, Russell E, Kim J-H, Chen Q, Brad Johnson F, et al. Aging alters bone-fat reciprocity by shifting in vivo mesenchymal precursor cell fate towards an adipogenic lineage. Bone (2016) 85:29-36. doi:10.1016/j. bone.2016.01.014

61. Zhou BO, Yue R, Murphy MM, Peyer JG, Morrison SJ. Leptin-receptorexpressing mesenchymal stromal cells represent the main source of bone formed by adult bone marrow. Cell Stem Cell (2014) 15:154-68. doi:10.1016/j. stem.2014.06.008

62. Liu Y, Strecker S, Wang L, Kronenberg MS, Wang W, Rowe DW, et al. Osterixcre labeled progenitor cells contribute to the formation and maintenance of the bone marrow stroma. PLoS One (2013) 8:e71318. doi:10.1371/journal. pone. 0071318

63. Pan SY, Johnson KC, Ugnat A-M, Wen SW, Mao Y. Association of obesity and cancer risk in Canada. Am J Epidemiol (2004) 159:259-68. doi:10.1093/ aje/kwh041
64. Wallin A, Larsson SC. Body mass index and risk of multiple myeloma: a meta-analysis of prospective studies. Eur J Cancer (2011) 47:1606-15. doi:10.1016/j.ejca.2011.01.020

65. Islam R, Altundag K, Kurt M, Altundag O, Turen S. Association between obesity and multiple myeloma in postmenopausal women may be attributed to increased aromatization of androgen in adipose tissue. Med Hypotheses (2005) 65:1001-2. doi:10.1016/j.mehy.2005.05.014

66. Caers J, Deleu S, Belaid Z, De Raeve H, Van Valckenborgh E, De Bruyne E, et al. Neighboring adipocytes participate in the bone marrow microenvironment of multiple myeloma cells. Leukemia (2007) 21:1580-4. doi:10.1038/ sj.leu. 2404658

67. Liu Z, Xu J, He J, Liu H, Lin P, Wan X, et al. Mature adipocytes in bone marrow protect myeloma cells against chemotherapy through autophagy activation. Oncotarget (2015) 6:34329-41. doi:10.18632/oncotarget.6020

68. Sprynski AC, Hose D, Caillot L, Réme T, Shaughnessy JD, Barlogie B, et al. The role of IGF-1 as a major growth factor for myeloma cell lines and the prognostic relevance of the expression of its receptor. Blood (2009) 113:4614-26. doi:10.1182/blood-2008-07-170464

69. Clark R, Krishnan V, Schoof M, Rodriguez I, Theriault B, Chekmareva M, et al. Milky spots promote ovarian cancer metastatic colonization of peritoneal adipose in experimental models. Am J Pathol (2013) 183:576-91. doi:10.1016/j.ajpath.2013.04.023

70. Vogl DT, Wang T, Pérez WS, Stadtmauer EA, Heitjan DF, Lazarus HM, et al. Effect of obesity on outcomes after autologous hematopoietic stem cell transplantation for multiple myeloma. Biol Blood Marrow Transplant (2011) 17:1765-74. doi:10.1016/j.bbmt.2011.05.005

71. Zub KA, Sousa MM, Sarno A, Sharma A, Demirovic A, Rao S, et al. Modulation of cell metabolic pathways and oxidative stress signaling contribute to acquired melphalan resistance in multiple myeloma cells. PLoS One (2015) 10:e0119857. doi:10.1371/journal.pone.0119857

72. Nagata Y, Ishizaki I, Waki M, Ide Y, Hossen MA, Ohnishi K, et al. Palmitic acid, verified by lipid profiling using secondary ion mass spectrometry, demonstrates anti-multiple myeloma activity. Leuk Res (2015) 39:638-45. doi:10.1016/j.leukres.2015.02.011

73. Zou J, Ma X, Zhang G, Shen L, Zhou L, Yu Y, et al. Evaluation of the change in sphingolipids in the human multiple myeloma cell line U266 and gastric cancer cell line MGC-803 treated with arsenic trioxide. JChromatogr B Analyt Technol Biomed Life Sci (2015) 1004:98-107. doi:10.1016/j. jchromb.2015.09.015

74. Kitatani K, Taniguchi M, Okazaki T. Role of sphingolipids and metabolizing enzymes in hematological malignancies. Mol Cells (2015) 38:482-95. doi:10.14348/molcells.2015.0118

75. Jurczyszyn A, Czepiel J, Gdula-Argasińska J, Paśko P, Czapkiewicz A, Librowski T, et al. Plasma fatty acid profile in multiple myeloma patients. Leuk Res (2015) 39:400-5. doi:10.1016/j.leukres.2014.12.010

76. Hossen MA, Nagata Y, Waki M, Ide Y, Takei S, Fukano H, et al. Decreased level of phosphatidylcholine (16:0/20:4) in multiple myeloma cells compared to plasma cells: a single-cell MALDI-IMS approach. Anal Bioanal Chem (2015) 407:5273-80. doi:10.1007/s00216-015-8741-z

77. Spindler TJ, Tseng AW, Zhou X, Adams GB. Adipocytic cells augment the support of primitive hematopoietic cells in vitro but have no effect in the bone marrow niche under homeostatic conditions. Stem Cells Dev (2014) 23:434-41. doi:10.1089/scd.2013.0227

78. Sola B, Poirot M, de Medina P, Bustany S, Marsaud V, Silvente-Poirot S, et al. Antiestrogen-binding site ligands induce autophagy in myeloma cells that proceeds through alteration of cholesterol metabolism. Oncotarget (2013) 4:911-22. doi:10.18632/oncotarget.1066

79. Nair S, Branagan AR, Liu J, Boddupalli CS, Mistry PK, Dhodapkar MV. Clonal immunoglobulin against lysolipids in the origin of myeloma. $N$ Engl J Med (2016) 374:555-61. doi:10.1056/NEJMoa1508808

80. Vescio RA, Cao J, Hong CH, Lee JC, Wu CH, Der Danielian M, et al. Myeloma Ig heavy chain $\mathrm{V}$ region sequences reveal prior antigenic selection and marked somatic mutation but no intraclonal diversity. J Immunol (1995) 155:2487-97.

81. Klein-Wieringa IR, Andersen SN, Kwekkeboom JC, Giera M, de LangeBrokaar BJE, van Osch GJVM, et al. Adipocytes modulate the phenotype of human macrophages through secreted lipids. J Immunol (2013) 191:1356-63. doi:10.4049/jimmunol.1203074 
82. Krishnan A, Nair SA, Pillai MR. Biology of PPAR gamma in cancer: a critical review on existing lacunae. Curr Mol Med (2007) 7:532-40. doi:10.2174/156652407781695765

83. Aouali N, Broukou A, Bosseler M, Keunen O, Schlesser V, Janji B, et al. Epigenetic activity of peroxisome proliferator-activated receptor gamma agonists increases the anticancer effect of histone deacetylase inhibitors on multiple myeloma cells. PLoS One (2015) 10:e0130339. doi:10.1371/journal. pone. 0130339

84. Rui M, Huang Z, Liu Y, Wang Z, Liu R, Fu J, et al. Rosiglitazone suppresses angiogenesis in multiple myeloma via downregulation of hypoxia-inducible factor- $1 \alpha$ and insulin-like growth factor-1 mRNA expression. Mol Med Rep (2014) 10:2137-43. doi:10.3892/mmr.2014.2407

85. Cao D, Zhou H, Zhao J, Jin L, Yu W, Yan H, et al. PGC-1 $\alpha$ integrates glucose metabolism and angiogenesis in multiple myeloma cells by regulating VEGF and GLUT-4. Oncol Rep (2014) 31:1205-10. doi:10.3892/or.2014.2974

86. Kim SY, Min HJ, Park HK, Oh B, Kim TY, She CJ, et al. Increased copy number of the interleukin- 6 receptor gene is associated with adverse survival in multiple myeloma patients treated with autologous stem cell transplantation. Biol Blood Marrow Transplant (2011) 17:810-20. doi:10.1016/j.bbmt.2011.01.002

87. Greco EA, Lenzi A, Migliaccio S. The obesity of bone. Ther Adv Endocrinol Metab (2015) 6:273-86. doi:10.1177/2042018815611004

88. Sakurai T, Ogasawara J, Kizaki T, Sato S, Ishibashi Y, Takahashi M, et al. The effects of exercise training on obesity-induced dysregulated expression of adipokines in white adipose tissue. Int J Endocrinol (2013) 2013:801743. doi:10.1155/2013/801743

89. Galson DL, Silbermann R, Roodman GD. Mechanisms of multiple myeloma bone disease. Bonekey Rep (2012) 1:135. doi:10.1038/bonekey.2012.135

90. Lee C, Oh J-I, Park J, Choi J-H, Bae E-K, Lee HJ, et al. TNF $\alpha$ mediated IL-6 secretion is regulated by JAK/STAT pathway but not by MEK phosphorylation and AKT phosphorylation in U266 multiple myeloma cells. Biomed Res Int (2013) 2013:580135. doi:10.1155/2013/580135

91. Jöhrer K, Janke K, Krugmann J, Fiegl M, Greil R. Transendothelial migration of myeloma cells is increased by tumor necrosis factor (TNF)-alpha via TNF receptor 2 and autocrine up-regulation of MCP-1. Clin Cancer Res (2004) 10:1901-10. doi:10.1158/1078-0432.CCR-1053-03

92. Yağci M, Sucak GT, Haznedar R. Fibrinolytic activity in multiple myeloma. Am J Hematol (2003) 74:231-7. doi:10.1002/ajh.10433

93. Schwartz MW, Woods SC, Porte D, Seeley RJ, Baskin DG. Central nervous system control of food intake. Nature (2000) 404:661-71. doi:10.1038/ 35007534

94. Ouchi N, Parker JL, Lugus JJ, Walsh K. Adipokines in inflammation and metabolic disease. Nat Rev Immunol (2011) 11:85-97. doi:10.1038/nri2921

95. Jarrar MH, Baranova A, Collantes R, Ranard B, Stepanova M, Bennett C, et al. Adipokines and cytokines in non-alcoholic fatty liver disease. Aliment Pharmacol Ther (2007) 27:412-21. doi:10.1111/j.1365-2036.2007.03586.x

96. Mattu HS, Randeva HS. Role of adipokines in cardiovascular disease. J Endocrinol (2012) 216:T17-36. doi:10.1530/JOE-12-0232

97. Sood A. Obesity, adipokines, and lung disease. J Appl Physiol (2009) 108:744-53. doi:10.1152/japplphysiol.00838.2009

98. Waluga M, Hartleb M, Boryczka G, Kukla M, Zwirska-Korczala K. Serum adipokines in inflammatory bowel disease. World J Gastroenterol (2014) 20:6912-7. doi:10.3748/wjg.v20.i22.6912

99. Hofmann JN, Liao LM, Pollak MN, Wang YY, Pfeiffer RM, Baris D, et al. A prospective study of circulating adipokine levels and risk of multiple myeloma. Blood (2012) 120:4418-20. doi:10.1182/blood-2012-06-438606

100. Reseland JE, Reppe S, Olstad OK, Hjorth-Hansen H, Brenne AT, Syversen U, et al. Abnormal adipokine levels and leptin-induced changes in gene expression profiles in multiple myeloma. Eur J Haematol (2009) 83:460-70. doi:10.1111/j.1600-0609.2009.01311.x

101. Dalamaga M, Diakopoulos KN, Mantzoros CS. The role of adiponectin in cancer: a review of current evidence. Endocr Rev (2012) 33:547-94. doi:10.1210/er.2011-1015

102. Alexandrakis MG, Passam FH, Sfiridaki A, Pappa CA, Moschandrea JA, Kandidakis E, et al. Serum levels of leptin in multiple myeloma patients and its relation to angiogenic and inflammatory cytokines. Int J Biol Markers (2004) 19:52-7.

103. Mouzaki A, Panagoulias I, Dervilli Z, Zolota V, Spadidea P, Rodi M, et al. Expression patterns of leptin receptor (OB-R) isoforms and direct in vitro effects of recombinant leptin on OB-R, leptin expression and cytokine secretion by human hematopoietic malignant cells. Cytokine (2009) 48:203-11. doi:10.1016/j.cyto.2009.07.006

104. Berner HS, Lyngstadaas SP, Spahr A, Monjo M, Thommesen L, Drevon CA, et al. Adiponectin and its receptors are expressed in bone-forming cells. Bone (2004) 35:842-9. doi:10.1016/j.bone.2004.06.008

105. Arita Y, Kihara S, Ouchi N, Takahashi M, Maeda K, Miyagawa J, et al. Paradoxical decrease of an adipose-specific protein, adiponectin, in obesity. Biochem Biophys Res Commun (1999) 257:79-83. doi:10.1006/bbrc.1999.0255

106. Hotta K, Funahashi T, Arita Y, Takahashi M, Matsuda M, Okamoto Y, et al. Plasma concentrations of a novel, adipose-specific protein, adiponectin, in type 2 diabetic patients. Arterioscler Thromb Vasc Biol (2000) 20:1595-9. doi:10.1161/01.ATV.20.6.1595

107. Kern PA, Di Gregorio GB, Lu T, Rassouli N, Ranganathan G. Adiponectin expression from human adipose tissue: relation to obesity, insulin resistance, and tumor necrosis factor-expression. Diabetes (2003) 52:1779-85. doi:10.2337/diabetes.52.7.1779

108. Dalamaga M, Karmaniolas K, Panagiotou A, Hsi A, Chamberland J, Dimas C, et al. Low circulating adiponectin and resistin, but not leptin, levels are associated with multiple myeloma risk: a case-control study. Cancer Causes Control (2009) 20:193-9. doi:10.1007/s10552-008-9233-7

109. Miyoshi Y, Funahashi T, Kihara S, Taguchi T, Tamaki Y, Matsuzawa Y, et al. Association of serum adiponectin levels with breast cancer risk. Clin Cancer Res (2003) 9:5699-704.

110. Fowler JA, Lwin ST, Drake MT, Edwards JR, Kyle RA, Mundy GR, et al. Host-derived adiponectin is tumor-suppressive and a novel therapeutic target for multiple myeloma and the associated bone disease. Blood (2011) 118:5872-82. doi:10.1182/blood-2011-01-330407

111. Medina EA, Oberheu K, Polusani SR, Ortega V, Velagaleti GVN, Oyajobi BO. PKA/AMPK signaling in relation to adiponectin's antiproliferative effect on multiple myeloma cells. Leukemia (2014) 28:2080-9. doi:10.1038/ leu.2014.112

112. Zhou Y, Rui L. Leptin signaling and leptin resistance. Front Med (2013) 7:207-22. doi:10.1007/s11684-013-0263-5

113. Montague CT, Farooqi IS, Whitehead JP, Soos MA, Rau H, Wareham NJ, et al. Congenital leptin deficiency is associated with severe early-onset obesity in humans. Nature (1997) 387:903-8. doi:10.1038/43185

114. Farooqi IS, Jebb SA, Langmack G, Lawrence E, Cheetham CH, Prentice AM, et al. Effects of recombinant leptin therapy in a child with congenital leptin deficiency. N Engl JMed (1999) 341:879-84. doi:10.1056/NEJM 199909163411204

115. Kopelman PG. Obesity as a medical problem. Nature (2000) 404:635-43. doi: $10.1038 / 35007508$

116. Hoang B, Benavides A, Shi Y, Frost P, Lichtenstein A. Effect of autophagy on multiple myeloma cell viability. Mol Cancer Ther (2009) 8:1974-84. doi:10.1158/1535-7163.MCT-08-1177

117. Arner P. Resistin: yet another adipokine tells us that men are not mice. Diabetologia (2005) 48:2203-5. doi:10.1007/s00125-005-1956-3

118. Ukkola O. Resistin - a mediator of obesity-associated insulin resistance or an innocent bystander? Eur J Endocrinol (2002) 147:571-4. doi:10.1530/ eje.0.1470571

119. Sprynski AC, Hose D, Kassambara A, Vincent L, Jourdan M, Rossi JF, et al. Insulin is a potent myeloma cell growth factor through insulin/IGF-1 hybrid receptor activation. Leukemia (2010) 24:1940-50. doi:10.1038/leu. 2010.192

120. Spencer JA, Ferraro F, Roussakis E, Klein A, Wu J, Runnels JM, et al. Direct measurement of local oxygen concentration in the bone marrow of live animals. Nature (2014) 508:269-73. doi:10.1038/nature13034

121. Amorin B, Alegretti AP, de Souza Valim V, da Silva AMP, da Silva MAL, Sehn F, et al. Characteristics of mesenchymal stem cells under hypoxia. CellBio (2013) 2:11-9. doi:10.4236/cellbio.2013.21002

122. Kakudo N, Morimoto N, Ogawa T, Taketani S, Kusumoto K. Hypoxia enhances proliferation of human adipose-derived stem cells via HIF-1a activation. PLoS One (2015) 10:e0139890. doi:10.1371/journal.pone. 0139890

123. Borsi E, Perrone G, Terragna C, Martello M, Dico AF, Solaini G, et al. Hypoxia inducible factor-1 alpha as a therapeutic target in multiple myeloma. Oncotarget (2014) 5:1779-92. doi:10.18632/oncotarget.1736 
124. Yata K, Otsuki T, Kurebayashi J, Uno M, Fujii T, Yawata Y, et al. Expression of angiogenic factors including VEGFs and the effects of hypoxia and thalidomide on human myeloma cells. Int J Oncol (2003) 22:165-73. doi:10.3892/ ijo.22.1.165

125. Muz B, de la Puente P, Azab F, Luderer M, Azab AK. Hypoxia promotes stem cell-like phenotype in multiple myeloma cells. Blood Cancer J (2014) 4:e262. doi:10.1038/bcj.2014.82

126. Azab AK, Hu J, Quang P, Azab F, Pitsillides C, Awwad R, et al. Hypoxia promotes dissemination of multiple myeloma through acquisition of epithelial to mesenchymal transition-like features. Blood (2012) 119:5782-94. doi:10.1182/blood-2011-09-380410

127. Zhang Y, Marsboom G, Toth PT, Rehman J. Mitochondrial respiration regulates adipogenic differentiation of human mesenchymal stem cells. PLoS One (2013) 8:e77077. doi:10.1371/journal.pone.0077077

128. Cicione C, Muiños-López E, Hermida-Gómez T, Fuentes-Boquete I, DíazPrado S, Blanco FJ. Effects of severe hypoxia on bone marrow mesenchymal stem cells differentiation potential. Stem Cells Int (2013) 2013:232896. doi:10.1155/2013/232896

129. Pachón-Peña G, Serena C, Ejarque M, Petriz J, Duran X, Oliva-Olivera W, et al. Obesity determines the immunophenotypic profile and functional characteristics of human mesenchymal stem cells from adipose tissue. Stem Cells Transl Med (2016) 5:464-75. doi:10.5966/sctm.2015-0161

130. Wu C-L, Diekman BO, Jain D, Guilak F. Diet-induced obesity alters the differentiation potential of stem cells isolated from bone marrow, adipose tissue and infrapatellar fat pad: the effects of free fatty acids. Int J Obes (Lond) (2013) 37:1079-87. doi:10.1038/ijo.2012.171

131. Hu J, Van Valckenborgh E, Menu E, De Bruyne E, Vanderkerken K. Understanding the hypoxic niche of multiple myeloma: therapeutic implications and contributions of mouse models. Dis Model Mech (2012) 5:763-71. doi:10.1242/dmm.008961

132. Forsythe JA, Jiang BH, Iyer NV, Agani F, Leung SW, Koos RD, et al. Activation of vascular endothelial growth factor gene transcription by hypoxia-inducible factor 1. Mol Cell Biol (1996) 16:4604-13. doi:10.1128/MCB.16.9.4604

133. Podar K, Anderson KC. The pathophysiologic role of VEGF in hematologic malignancies: therapeutic implications. Blood (2005) 105:1383-95. doi:10.1182/blood-2004-07-2909

134. Yaccoby S, Barlogie B, Epstein J. Primary myeloma cells growing in SCID-hu mice: a model for studying the biology and treatment of myeloma and its manifestations. Blood (1998) 92:2908-13.

135. Bolkun L, Lemancewicz D, Sobolewski K, Mantur M, Semeniuk J, Kulczynska A, et al. The evaluation of angiogenesis and matrix metalloproteinase-2 secretion in bone marrow of multiple myeloma patients before and after the treatment. Adv Med Sci (2013) 58:118-25. doi:10.2478/ v10039-012-0048-0

136. Zhang QX, Magovern CJ, Mack CA, Budenbender KT, Ko W, Rosengart TK. Vascular endothelial growth factor is the major angiogenic factor in omentum: mechanism of the omentum-mediated angiogenesis. J Surg Res (1997) 67:147-54. doi:10.1006/jsre.1996.4983

137. Soukas A, Socci ND, Saatkamp BD, Novelli S, Friedman JM. Distinct transcriptional profiles of adipogenesis in vivo and in vitro. J Biol Chem (2001) 276:34167-74. doi:10.1074/jbc.M104421200

138. Baek JH, Jang JE, Kang CM, Chung HY, Kim ND, Kim KW. Hypoxiainduced VEGF enhances tumor survivability via suppression of serum deprivation-induced apoptosis. Oncogene (2000) 19:4621-31. doi:10.1038/ sj.onc. 1203814

139. Wang F, Zhang W, Guo L, Bao W, Jin N, Liu R, et al. Gambogic acid suppresses hypoxia-induced hypoxia-inducible factor- $1 \alpha /$ vascular endothelial growth factor expression via inhibiting phosphatidylinositol 3-kinase/Akt/ mammalian target protein of rapamycin pathway in multiple myeloma cells. Cancer Sci (2014) 105:1063-70. doi:10.1111/cas.12458

140. de Waal EGM, Slart RHJA, Leene MJ, Kluin PM, Vellenga E. 18F-FDG PET increases visibility of bone lesions in relapsed multiple myeloma: is this hypoxia-driven? Clin Nucl Med (2015) 40:291-6. doi:10.1097/ RLU.0000000000000629

141. Almendros I, Gileles-Hillel A, Khalyfa A, Wang Y, Zhang SX, Carreras A, et al. Adipose tissue macrophage polarization by intermittent hypoxia in a mouse model of OSA: effect of tumor microenvironment. Cancer Lett (2015) 361:233-9. doi:10.1016/j.canlet.2015.03.010
142. Kugel H, Jung C, Schulte O, Heindel W. Age- and sex-specific differences in the $1 \mathrm{H}$-spectrum of vertebral bone marrow. J Magn Reson Imaging (2001) 13: 263-8. doi:10.1002/1522-2586(200102)13:2<263::AID-JMRI1038>3.3.CO;2-D

143. Griffith JF, Yeung DKW, Antonio GE, Wong SYS, Kwok TCY, Woo J, et al. Vertebral marrow fat content and diffusion and perfusion indexes in women with varying bone density: MR evaluation. Radiology (2006) 241:831-8. doi:10.1148/radiol.2413051858

144. Griffith JF, Yeung DKW, Antonio GE, Lee FKH, Hong AWL, Wong SYS, et al. Vertebral bone mineral density, marrow perfusion, and fat content in healthy men and men with osteoporosis: dynamic contrast-enhanced MR imaging and MR spectroscopy. Radiology (2005) 236:945-51. doi:10.1148/ radiol.2363041425

145. Schwartz AV, Sigurdsson S, Hue TF, Lang TF, Harris TB, Rosen CJ, et al. Vertebral bone marrow fat associated with lower trabecular BMD and prevalent vertebral fracture in older adults. J Clin Endocrinol Metab (2013) 98:2294-300. doi:10.1210/jc.2012-3949

146. McGee-Lawrence ME, Carpio LR, Schulze RJ, Pierce JL, McNiven MA, Farr JN, et al. Hdac3 deficiency increases marrow adiposity and induces lipid storage and glucocorticoid metabolism in osteochondroprogenitor cells. J Bone Miner Res (2015) 31:116-28. doi:10.1002/jbmr.2602

147. Sinha P, Aarnisalo P, Chubb R, Ono N, Fulzele K, Selig M, et al. Loss of Gs $\alpha$ early in the osteoblast lineage favors adipogenic differentiation of mesenchymal progenitors and committed osteoblast precursors. J Bone Miner Res (2014) 29:2414-26. doi:10.1002/jbmr.2270

148. Urs S, Henderson T, Le P, Rosen CJ, Liaw L. Tissue-specific expression of Sproutyl in mice protects against high-fat diet-induced fat accumulation, bone loss and metabolic dysfunction. Br J Nutr (2012) 108:1025-33. doi:10.1017/S0007114511006209

149. Motyl KJ, Raetz M, Tekalur SA, Schwartz RC, McCabe LR. CCAAT/ enhancer binding protein $\beta$-deficiency enhances type 1 diabetic bone phenotype by increasing marrow adiposity and bone resorption. Am J Physiol Regul Integr Comp Physiol (2011) 300:R1250-60. doi:10.1152/ajpregu.007 64.2010

150. Colaianni G, Brunetti G, Faienza MF, Colucci S, Grano M. Osteoporosis and obesity: role of Wnt pathway in human and murine models. World J Orthop (2014) 5:242-6. doi:10.5312/wjo.v5.i3.242

151. de Paula FJA, de Araújo IM, Carvalho AL, Elias J, Salmon CEG, NogueiraBarbosa MH. The relationship of fat distribution and insulin resistance with lumbar spine bone mass in women. PLoS One (2015) 10:e129764. doi:10.1371/journal.pone.0129764

152. Templeton ZS, Lie W-R, Wang W, Rosenberg-Hasson Y, Alluri RV, Tamaresis JS, et al. Breast cancer cell colonization of the human bone marrow adipose tissue niche. Neoplasia (2015) 17:849-61. doi:10.1016/j. neo.2015.11.005

153. Takeshita S, Fumoto T, Naoe Y, Ikeda K. Age-related marrow adipogenesis is linked to increased expression of RANKL. J Biol Chem (2014) 289:16699-710. doi:10.1074/jbc.M114.547919

154. Wang D, Haile A, Jones LC. Dexamethasone-induced lipolysis increases the adverse effect of adipocytes on osteoblasts using cells derived from human mesenchymal stem cells. Bone (2013) 53:520-30. doi:10.1016/j. bone.2013.01.009

155. Kajimura D, Lee HW, Riley KJ, Arteaga-Solis E, Ferron M, Zhou B, et al. Adiponectin regulates bone mass via opposite central and peripheral mechanisms through foxo1. Cell Metab (2013) 17:901-15. doi:10.1016/j. cmet.2013.04.009

156. Kennedy DE, Knight KL. Inhibition of B lymphopoiesis by adipocytes and IL-1-producing myeloid-derived suppressor cells. J Immunol (2015) 195:2666-74. doi:10.4049/jimmunol.1500957

157. Arnulf B, Lecourt S, Soulier J, Ternaux B, Lacassagne M-N, Crinquette A, et al. Phenotypic and functional characterization of bone marrow mesenchymal stem cells derived from patients with multiple myeloma. Leukemia (2007) 21:158-63. doi:10.1038/sj.leu.2404466

158. Nieman KM, Kenny HA, Penicka CV, Ladanyi A, Buell-Gutbrod R, Zillhardt MR, et al. Adipocytes promote ovarian cancer metastasis and provide energy for rapid tumor growth. Nat Med (2011) 17:1498-503. doi: $10.1038 / \mathrm{nm} .2492$

159. Gavin KM, Gutman JA, Kohrt WM, Wei Q, Shea KL, Miller HL, et al. De novo generation of adipocytes from circulating progenitor cells in mouse 
and human adipose tissue. FASEB J (2015) 30:1096-108. doi:10.1096/ f.15-278994

160. Devlin MJ, Rosen CJ. The bone-fat interface: basic and clinical implications of marrow adiposity. Lancet Diabetes Endocrinol (2015) 3:141-7. doi:10.1016/ S2213-8587(14)70007-5

161. Ford NA, Devlin KL, Lashinger LM, Hursting SD. Deconvoluting the obesity and breast cancer link: secretome, soil and seed interactions. J Mammary Gland Biol Neoplasia (2013) 18:267-75. doi:10.1007/s10911-013-9301-9

162. DinarelloCA. Interleukin-1 in thepathogenesisand treatment ofinflammatory diseases. Blood (2011) 117:3720-32. doi:10.1182/blood-2010-07-273417

163. Liou Y-H, Wang S-W, Chang C-L, Huang P-L, Hou M-S, Lai Y-G, et al. Adipocyte IL-15 regulates local and systemic NK cell development. J Immunol (2014) 193:1747-58. doi:10.4049/jimmunol.1400868

164. Szmania S, Lapteva N, Garg T, Greenway A, Lingo J, Nair B, et al. Ex vivoexpanded natural killer cells demonstrate robust proliferation in vivo in highrisk relapsed multiple myeloma patients. J Immunother (2015) 38:24-36. doi:10.1097/CJI.0000000000000059

165. Rezzadeh KS, Hokugo A, Jewett A, Kozlowska A, Segovia LA, Zuk P, et al. Natural killer cells differentiate human adipose-derived stem cells and modulate their adipogenic potential. Plast Reconstr Surg (2015) 136:503-10. doi:10.1097/PRS.0000000000001536

166. Hardaway AL, Herroon MK, Rajagurubandara E, Podgorski I. Bone marrow fat: linking adipocyte-induced inflammation with skeletal metastases. Cancer Metastasis Rev (2014) 33:527-43. doi:10.1007/s10555-013-9484-y

167. Yin H, Xu L, Porter NA. Free radical lipid peroxidation: mechanisms and analysis. Chem Rev (2011) 111:5944-72. doi:10.1021/cr200084z

168. Esterbauer H, Eckl P, Ortner A. Possible mutagens derived from lipids and lipid precursors. Mutat Res (1990) 238:223-33. doi:10.1016/0165-1110 (90)90014-3

169. Chalhoub N, Baker SJ. PTEN and the PI3-kinase pathway in cancer. Annu Rev Pathol (2009) 4:127-50. doi:10.1146/annurev.pathol.4.110807.092311

170. Martinez-Useros J, Garcia-Foncillas J. Obesity and colorectal cancer: molecular features of adipose tissue. J Transl Med (2016) 14:21. doi:10.1186/ s12967-016-0772-5

171. Eda H, Santo L, Wein MN, Hu DZ, Cirstea DD, Nemani N, et al. Regulation of sclerostin expression in multiple myeloma by Dkk-1; a potential therapeutic strategy for myeloma bone disease. J Bone Miner Res (2016) 31(6):1225-34. doi:10.1002/jbmr.2789

172. Brunetti G, Oranger A, Mori G, Specchia G, Rinaldi E, Curci P, et al. Sclerostin is overexpressed by plasma cells from multiple myeloma patients. Ann N Y Acad Sci (2011) 1237:19-23. doi:10.1111/j.1749-6632.2011.06196.x

173. Urs S, Venkatesh D, Tang Y, Henderson T, Yang X, Friesel RE, et al. Sproutyl is a critical regulatory switch of mesenchymal stem cell lineage allocation. FASEB J (2010) 24:3264-73. doi:10.1096/f. 10-155127
174. Wei S, Zhang L, Zhou X, Du M, Jiang Z, Hausman GJ, et al. Emerging roles of zinc finger proteins in regulating adipogenesis. Cell Mol Life Sci (2013) 70:4569-84. doi:10.1007/s00018-013-1395-0

175. Shen W, Velasquez G, Chen J, Jin Y, Heymsfield SB, Gallagher D, et al. Comparison of the relationship between bone marrow adipose tissue and volumetric bone mineral density in children and adults. JClin Densitom (2014) 17:163-9. doi:10.1016/j.jocd.2013.02.009

176. Martin RB, Zissimos SL. Relationships between marrow fat and bone turnover in ovariectomized and intact rats. Bone (1991) 12:123-31. doi:10.1016/8756-3282(91)90011-7

177. Bonnet N, Somm E, Rosen CJ. Diet and gene interactions influence the skeletal response to polyunsaturated fatty acids. Bone (2014) 68:100-7. doi:10.1016/j.bone.2014.07.024

178. Styner M, Pagnotti GM, Galior K, Wu X, Thompson WR, Uzer G, et al. Exercise regulation of marrow fat in the setting of PPAR $\gamma$ agonist treatment in female C57BL/6 mice. Endocrinology (2015) 156:2753-61. doi:10.1210/ en.2015-1213

179. Meier C, Schwartz AV, Egger A, Lecka-Czernik B. Effects of diabetes drugs on the skeleton. Bone (2016) 82:93-100. doi:10.1016/j.bone.2015.04.026

180. Hanson DJ, Nakamura S, Amachi R, Hiasa M, Oda A, Tsuji D, et al. Effective impairment of myeloma cells and their progenitors by blockade of monocarboxylate transportation. Oncotarget (2015) 6:33568-86. doi:10.18632/ oncotarget. 5598

181. Kasznicki J, Sliwinska A, Drzewoski J. Metformin in cancer prevention and therapy. Ann Transl Med (2014) 2:57. doi:10.3978/j.issn.2305-5839. 2014.06.01

182. Abdi J, Garssen J, Faber J, Redegeld FA. Omega-3 fatty acids, EPA and DHA induce apoptosis and enhance drug sensitivity in multiple myeloma cells but not in normal peripheral mononuclear cells. J Nutr Biochem (2014) 25:1254-62. doi:10.1016/j.jnutbio.2014.06.013

183. Jia L, Liu F-T. Why bortezomib cannot go with "green"? Cancer Biol Med (2013) 10:206-13. doi:10.7497/j.issn.2095-3941.2013.04.004

Conflict of Interest Statement: The authors declare that the research was conducted in the absence of any commercial or financial relationships that could be construed as a potential conflict of interest.

Copyright (c) 2016 Falank, Fairfield and Reagan. This is an open-access article distributed under the terms of the Creative Commons Attribution License (CC BY). The use, distribution or reproduction in other forums is permitted, provided the original author(s) or licensor are credited and that the original publication in this journal is cited, in accordance with accepted academic practice. No use, distribution or reproduction is permitted which does not comply with these terms. 